\title{
The nephroureterectomy: a review of technique and current controversies
}

\author{
Gregory J. Barton ${ }^{1}$, Wei Phin Tan ${ }^{1}$, Brant A. Inman ${ }^{1,2}$ \\ ${ }^{1}$ Division of Urology, Duke University Medical Center, Durham, NC, USA; ${ }^{2}$ Duke Cancer Institute, Duke University Medical Center, Durham, \\ NC, USA \\ Contributions: (I) Conception and design: GJ Barton, BA Inman; (II) Administrative support: BA Inman; (III) Provision of study materials or patients: \\ All authors; (IV) Collection and assembly of data: GJ Barton; (V) Data analysis and interpretation: All authors; (VI) Manuscript writing: All authors; \\ (VII) Final approval of manuscript: All authors. \\ Correspondence to: Brant A. Inman, MD, MS, FRCSC. Cary N. Robertson Associate Professor of Urologic Oncology, Co-Director of Duke Prostate \\ and Urologic Cancer Center, Vice Chief of Urology, Box 103868, 3007 Snyderman Bldg, 905 La Salle Street, Durham, NC 27710, USA. \\ Email: brant.inman@duke.edu.
}

\begin{abstract}
The nephroureterectomy (NU) is the standard of care for invasive upper tract urothelial carcinoma (UTUC) and has been around for well over one hundred years. Since then new operative techniques have emerged, new technologies have developed, and the surgery continues to evolve and grow. In this article, we review the various surgical techniques, as well as present the literature surrounding current areas of debate surrounding the NU, including the lymphatic drainage of the upper urinary tract, management of UTUC involvement with the adrenals and caval thrombi, surgical management of the distal ureter, the use of intravesical chemotherapy as well as perioperative systemic chemotherapy, as well as various outcome measures. Although much has been studied about the NU, there still is a dearth of level 1 evidence and the field would benefit from further studies.
\end{abstract}

Keywords: Upper tract urothelial cancer; nephroureterectomy (NU); outcomes

Submitted Sep 18, 2019. Accepted for publication Dec 02, 2019.

doi: 10.21037/tau.2019.12.07

View this article at: http://dx.doi.org/10.21037/tau.2019.12.07

\section{Overview}

The nephroureterectomy surgery has been utilized for more than 100 years. In 1898, Dentu and Albarran described the first nephroureterectomy, which only involved removing a portion of the ureter (1). Kimball and Ferris subsequently noted tumor recurrences in the remaining distal portion of the ureter, and expressed the importance of resecting the entire ureter; from renal pelvis to the intramural ureter (2). In 1991 the first laparoscopic nephroureterectomy (LNU) was reported by Clayman (3). The first report of the use of a surgical robot for nephrectomy was reported in 2001, followed by the first robotic assisted heminephroureterectomy in 2004, although this was performed for recurrent infections and incontinence due to ectopic ureters, not upper tract urothelial carcinoma (UTUC) (4,5). In 2006, Nanigian et al. subsequently reported the first robotic-assisted laparoscopic nephroureterectomy (RANU) (6,7). For high-grade UTUC, radical nephroureterectomy has been and still is the standard of care. In this review, we describe the radical nephroureterectomy, specific nuances, areas of debate, outcomes, and the future of the procedure.

\section{Description of technique}

Nephroureterectomy is best categorized into two parts of the surgery: (I) radical nephrectomy and (II) distal ureterectomy (8). Each of these parts can be performed with 
an open or minimally invasive approach. Each approach has its own pros and cons as will be described below.

\section{Surgical approach}

Open nephroureterectomy (ONU) is the gold standard for the management of high-grade UTUC (9). Although only one randomized controlled trial (RCT) comparing surgical approaches (ONU to LNU) has been performed, many retrospective studies exist $(10,11)$. The majority, including the RCT, report shorter operative times for ONU when compared to LNU, 156-324 vs. 180-498 minutes, respectively (10). Operative time for RANU has not been directly compared to ONU or LNU, but reported times range 184-326 minutes (10). However, estimated blood loss (EBL) and hospital length of stay (LOS) tend to be lower in LNU and RANU than in ONU (130-479 $\mathrm{mL}$ and 2.313.5 days, $50-284 \mathrm{~mL}$ and $2.3-6.7$ days, $296-696 \mathrm{~mL}$ and 5.2-21.1 days, respectively) (10). Lymph node dissection (LND) is performed less frequently than RANU, but when performed, RANU had higher median node counts, as well as lower perioperative morbidity (12-14). Unfortunately, RANU is more expensive than LNU by $\sim \$ 5,500(\$ 23,235$ vs. \$17,637) (15).

\section{Nephrectomy}

In an ONU, single and two-incision techniques have been described. The pros and cons of each approach are detailed in Table 1. If a two-incision technique is used, the patient is placed in the flank position for the nephrectomy portion of the case. The nephrectomy is performed, although the ureter is not divided, just clipped, and after the ureteral dissection is taken as distally as possible (usually to the level of the common iliac artery), the patient needs to be repositioned to the supine position for the distal ureterectomy. Patient positioning for a single incision approach depends on the incision. For anterior incisions (midline laparotomy and paramedian laparotomy), the patient remains supine for the entirety of the case; however, for the thoracoabdominal incision, the patient is placed in the flank position for the nephrectomy portion and then is repositioned to supine for the distal ureterectomy (8).

In an LNU, for the skilled laparoscopic surgeon, the entire case can be performed pure lap. However, the distal ureteral dissection and bladder cuff resection can be quite challenging. For this reason, it is not uncommon for surgeons to perform the nephrectomy laparoscopically, and then perform the distal ureterectomy open. In a pure LNU, the patient is placed in a modified flank position and secured to the table in case it needs to be rotated to a supine position for the distal ureterectomy. The distal ureterectomy is better performed pure lap when the tumor is the renal pelvis or proximal ureter, and if the surgeon is skilled at laparoscopy. If the tumor is distal and/or the surgeon is uncomfortable performing the distal ureterectomy laparoscopically, the patient can be repositioned supine following the nephrectomy, and the distal ureterectomy treated in an open fashion. Port placement follows standard laparoscopic principles, wherein the ports are triangulated around the kidney, generally three or four trocars, depending on laterality (for right-sided tumors a fourth subxiphoid trocar for liver retraction can be placed). With obese patients, the template layout is shifted lateral of midline towards the lesion, or else the standard template shifts too far contralateral once the abdomen is insufflated (8).

An alternative to the LNU is the hand-assist laparoscopic nephroureterectomy (HALNU). The HALNU provides for more improved retraction during the nephrectomy which decreases operative time, and the hand port also serves as an extraction site as well as an open approach to the bladder cuff, if desired. Options for the hand port site include midline or Gibson incisions. The midline incision is more comfortable for the surgeon during nephrectomy, but the distal ureterectomy is more difficult. The Gibson incision, although more difficult and potentially uncomfortable during the nephrectomy, allows for a more facile open distal ureterectomy.

The RANU, although similar in technique to the LNU, provides improved visualization (10× magnification) and dexterity, which facilitates LND, as well as distal ureterectomy. However, due to limitations of the robotic arm placement and positioning, following the nephrectomy (performed in the flank position), the earlier platforms of the da Vinci robot (Intuitive Surgical, Inc., Sunnyvale, CA, USA) would need to be undocked, the patient re-positioned to supine, then the robot re-positioned and re-docked, significantly increasing operative time (16). However, with the da Vinci Si platform, novel port placements that eliminate the need for robot redocking were described, and the fourth generation platform, the da Vinci Xi, allows for improved ease with which to perform a single docking RANU, because it allows for the arm boom to swing to accommodate surgical needs, as well as the fact that the camera can be placed in any port, and the ports can be closer to each other than with the da Vinci Si (16-20). 
Table 1 Open NU approaches (8)

\begin{tabular}{|c|c|c|c|}
\hline Type & Incision & Advantages & Disadvantages \\
\hline \multirow{2}{*}{ Single } & & No repositioning & Increased morbidity, very large incision \\
\hline & & & $\begin{array}{l}\text { Violation of pleural cavity }=\text { increased risk of pulmonary } \\
\text { complications }\end{array}$ \\
\hline \multirow{2}{*}{ Single } & & Does not transect muscles & Large incision \\
\hline & & No repositioning & \\
\hline \multirow[t]{2}{*}{ Single } & Paramedian laparotomy & Provides good access to the aorta and IVC & Poorer access to upper pole \\
\hline & & No repositioning & Transects deep inferior epigastrics \\
\hline \multirow[t]{2}{*}{ Upper } & Flank & Allows for extraperitoneal approach & Requires repositioning for distal ureterectomy \\
\hline & & & Difficult LND \\
\hline Upper & Subcostal & Good access to hilar vessels & Requires repositioning for distal ureterectomy \\
\hline Lower & Gibson & $\begin{array}{l}\text { Can perform distal ureterectomy through it } \\
\text { also use as extraction site }\end{array}$ & Less comfortable for HALNU \\
\hline Lower & Midline or Pfannenstiel & No muscle transection & Will need to reposition from flank/subcostal incision \\
\hline
\end{tabular}

NU, nephroureterectomy; IVC, inferior vena cava; LND, lymph node dissection; HALNU, hand-assist laparoscopic nephroureterectomy.

\section{Distal ureterectomy}

The distal ureter and bladder cuff can be managed with an open, laparoscopic, or endoscopic method (21). Currently, there are no prospective RCTs comparing the approaches. The standard of care is complete resection of the entire distal ureter with a cuff of surrounding bladder tissue (9). Poorer cancer-specific survival (CSS) and overall survival (OS) has been seen in patients who did not have a bladder cuff excision (BCE) during their NU $(22,23)$. Furthermore, Phé et al. noted the importance of BCE on oncologic outcomes when reviewing the distal ureter management options (21). Some smaller studies call this into question, and as such they should be interpreted with caution. Ha et al. found no difference in CSS based on BCE status for all UTUC patients; however, when stratified by tumor location, BCE was associated with improved CSS with ureteral tumors but not with renal pelvis tumors (24). Lughezzani et al. found that with renal pelvis tumors, BCE improved CSS with $\geq \mathrm{pT} 3$ and/or pN+ patients, but there was no difference with $\leq \mathrm{pT} 2$ disease (25). Despite standard of care practices for BCE, not all urologists perform one. In a recent analysis of Surveillance, Epidemiology and End Results (SEER) data, Nazzani et al. found that in only $68 \%$ of 4,266 patients had a BCE at time of NU. Interestingly, they saw no difference in CSS regardless of BCE status (26).

Open distal ureterectomy has historically been considered the gold standard in NU because it allows for maximal control of distal ureteral disease during the procedure (27). Even in an LNU, surgeons may opt to still manage the distal ureter and bladder cuff in an open fashion. The HALNU lends itself to open management via the hand port incision, as noted above. However, significant controversy exists over the optimal approach to management.

In an open distal ureterectomy, the surgeon has the option to perform an intravesical or extravesical approach to remove the ureter and bladder cuff. The intravesical technique allows for excellent visualization of the intramural 


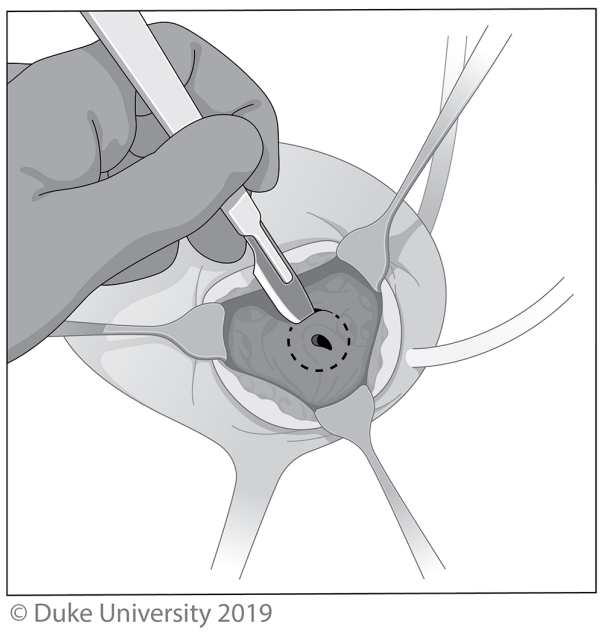

Figure 1 The open intravesical approach to the distal ureterectomy. Note the anterior cystotomy that provides access to make a circumferential incision around the ureteral orifice and intramural ureter.

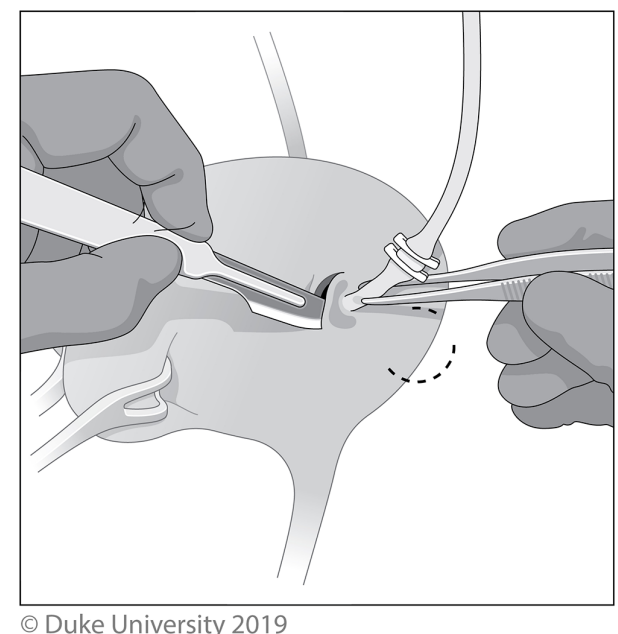

Figure 2 The open extravesical approach to the distal ureterectomy. Notice how access and visualization is poorer with this approach, but it is less morbid in that it avoids a second cystotomy.

ureter and bladder cuff, but at the expense of increased morbidity and longer catheterization owing to the two cystotomies required (21). A low midline incision is made, followed by an anterior cystotomy, which allows the surgeon to directly visualize the ureteral orifice and surrounding bladder cuff, shown in Figure 1. A circular incision is made $5-10 \mathrm{~mm}$ around the ureteric orifice and the intramural ureter is dissected until the proximal ureteral dissection is reached, allowing the specimen to be removed en bloc. The posterior and anterior bladder walls are then each closed in two layers.

The extravesical technique, shown in Figure 2 is less morbid, but visualization is poorer and the dissection of the intramural ureter and bladder cuff resection can be much more difficult, especially if a suboptimal incision is made (21). To start, a small low midline incision or Gibson incision is made and after identifying the ureter as it crosses the iliac vessels, the dissection continues distally to the intramural ureter, which is dissected out along with a $5-10-\mathrm{mm}$ bladder cuff. The specimen is removed en bloc and the bladder is closed in two layers.

Laparoscopic approaches generally utilize an extravesical approach. To complete the entire distal ureterectomy laparoscopically requires a skilled laparoscopic surgeon (21). A transvesical laparoscopic approach, using transvesically placed trocars to allow for passage of a resectoscope to perform a distal ureterectomy, has been described but is not widely used due to its difficulty (21).

Options for endoscopic management of the distal ureter/ bladder cuff include transurethral resection of the ureteral orifice (Pluck technique) and ureteral intussusception (Stripping technique). There are few studies comparing the different endoscopic approaches. Laguna et al. compared the endoscopic pluck to ureteral stripping and found no significant differences in intravesical recurrencefree survival (IVRS) between the two, but noted a higher complication rate with stripping (10\% vs. $2.7 \%)$ (28). The Pluck and Stripping techniques should not be used for distal or midureteral tumors due to the risk of tumor spillage and seeding. However, these approaches are designed to maximize the ease of the distal ureterectomy without the morbidity of larger incisions; both are performed with the patient in lithotomy (8). With endoscopic approaches, if the bladder is not closed, there is a risk of urine (and possibly tumor cell) spillage.

With the Pluck technique, either a Collins knife or loop resectoscope is used to circumferentially incise a $5-10-\mathrm{mm}$ cuff of bladder mucosa surrounding the ureteral orifice, shown in Figure 3. A urethral catheter is placed to minimize urine seepage through the residual cystotomy during the remainder of the case (8).

With the Stripping technique, a ureteral catheter is placed and the nephrectomy portion is then performed. The ureter is dissected as distally as possible, and then ligated cranial to the end of the ureteral catheter. Following 


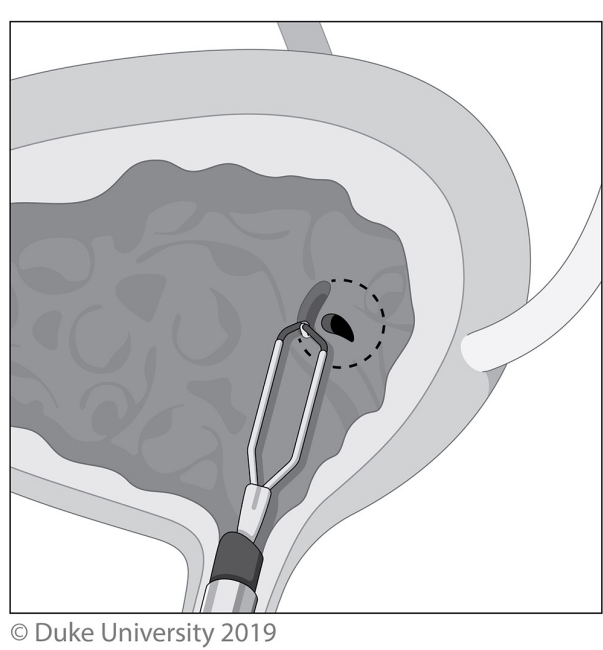

Figure 3 The endoscopic pluck technique. Here, the Collins knife is used to circumscribe around the ureteral orifice and intramural ureter. This can be "plucked" out at the conclusion of the distal ureteral dilation, and the bladder closed primarily or by secondary intention.

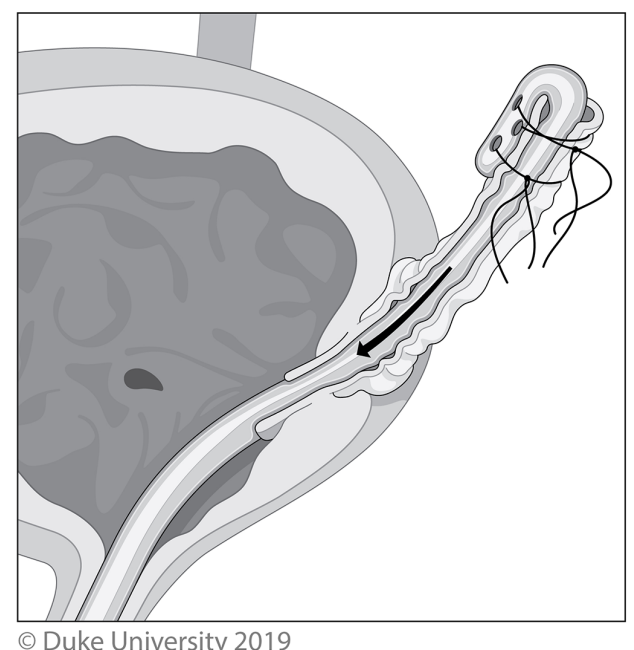

Figure 4 The Stripping technique. Note the ureteral catheter travels past the resected and open end of the ureter. It is then folded over on itself, stitched to the ureter, which allows for the entire distal ureter to be removed after resecting the intramural ureter and ureteral orifice endoscopically.

that, the ureter is cut between the ligation and the ureteral catheter. The ureteral catheter is pulled out of the end of the ureter, folded over itself, then secured to the ureter; this is shown in Figure 4. The patient is then placed back in lithotomy, a resectoscope is inserted, and the intramural ureter is resected to the peri-vesical fat. The catheter is then pulled out, bringing the intussuscepted ureter with it. A urethral catheter is placed and the bladder closes by secondary intention.

Many studies have attempted to compare outcomes between endoscopic approaches to open approaches to BCE management, with no clear consensus regarding optimal management. When comparing the approaches, a number of studies have found no difference in CSS or OS (29-36). However, these studies demonstrate differing findings with regards to intravesical recurrences (IVRs), or IVRS. In some studies, endoscopic management is associated with poorer IVRS $(30,32,36)$. Alternatively, no difference in IVRS is seen in competing studies $(23,29,31,35,37)$.

To further complicate the picture, some of those studies stratified their analyses by comparing intravesical (anterior cystotomy approach) to extravesical to endoscopic management and none were in complete agreement (2931,36,38). Xylinas et al. reported no significant difference between any of the approaches with regards to recurrencefree survival (RFS), CSS, or OS; but endoscopic management was associated with poorer IVRS when compared to either extravesical or intravesical management (36). Lee et al. reported that intravesical and extravesical management was associated with superior RFS and IVRS when compared to endoscopic management (39). Kapoor et al. found that intravesical management had superior RFS to either extravesical or endoscopic management, and interestingly, endoscopic and intravesical management was associated with better IVRS than extravesical management (38). To round out the differences, Allard et al. and Li et al. found no difference among any of the approaches with regards to RFS or IVRS $(29,31)$. Last, both Fragkoulis et al. and Walton et al. reported shorter operative times with endoscopic management $(35,37)$.

\section{Topics of debate}

While the surgical techniques described above are generally well accepted in the urologic community, there remains a number of factors related to the NU that require specific attention or engender strong debate. These are described further below.

\section{Lymphatic drainage \& nodal management}

It is thought that the lymphatic drainage of the upper 
urinary tract generally follows arterial supply (40). However, retrospective studies examining lymph node metastasis from the upper tract have added considerably to our knowledge of metastatic and drainage patterns. Kondo et al. was instrumental in reporting lymphatic drainage patterns using this method; the first of his three papers focused on this topic in 2007 reported that metastases involved lymph nodes based on laterality and site of the upper tract (renal pelvis, upper/mid ureter, and lower ureter). Notably, he reported that right-sided drainage, especially from the renal pelvis and proximal ureter, was broader than previously thought, involving the renal hilar, paracaval, and retrocaval nodes (41). In a follow up study assessing the impact of LND templates, he found that removing hilar, paracaval, retrocaval, and interaortocaval lymph nodes for right renal pelvis and upper/mid ureteral tumors, and hilar and paraaortic lymph nodes for left renal pelvis and upper/mid ureteral tumors was associated with improved CSS (42). In 2017, he described a lower ureteral tumor lymph node template regardless of tumor laterality, consisting of the common iliac, internal and external iliac, obturator, and presacral lymph nodes; however, no difference in RFS or CSS was seen with templated LND for lower ureteral tumors, despite improved RFS and CSS with templated LND for renal pelvis and upper/mid ureteral tumors (43).

Alvarez-Maestro et al. recently published a review of lymph node metastatic spread and noted predictable patterns similar to that of Kondo et al. (40). Matin et al. also noted similar metastatic patterns, importantly reporting that the right renal pelvis also drained to the inter-aortocaval lymph nodes, something that Kondo did not note in his 2007 study, but incorporated in later studies (44). The lymph node templates and outcomes are detailed in Table 2 and drainage patterns and visual representations of the templates are detailed in Figures 5,6, respectively.

Despite descriptions of LND templates, there are no prospective RCT on nodal management with UTUC. In 1997 Komatsu et al. first published the results of their experience with 36 patients who underwent NU with LND; 5 -year OS for $\mathrm{pN}+$ patients was $21 \%$, but there were no disease related pT0 patient deaths. They suggested that LND may provide some therapeutic benefit to select, low volume patients and may be a useful in staging UTUC (45). This conclusion was supported later by Roscigno et al. in 2011 in a larger review (46). Soon after, Miyake et al. described a retrospective series of 72 patients who underwent NU for UTUC, with 35 undergoing LND and 38 without LND. They found that there was no difference in OS when the two cohorts were compared; however, in patients without lymphovascular invasion, LND was associated with improved OS (47). This sparked a number of small studies assessing the oncologic outcomes associated with LND and LND yield, which are detailed in Table 3.

Multiple recent systematic reviews found that LND with advanced disease $(\geq \mathrm{pT} 2$ or $\geq \mathrm{pT} 3)$ was associated with improved CSS and increased lymph node yield (LNY) was associated with decreased mortality $(52,55,58,59)$. This culminated with a systematic review by the European Association of Urology (EAU) guidelines panel, who found that both template-based and complete LND improves tumor staging as well as CSS with $\geq$ pT2 UTUC and reduces local recurrences. They also reported incidences of $\mathrm{pN}+$ in $\mathrm{cN} 0 \geq$ pT2 patients ranging from $14.3 \%$ to $40 \%$ (54).

However, several other large-scale studies recently have found no improvement in CSS with LND. In a 2010 study of 2,824 SEER patients, Lughezzani et al. found no difference in 5-year CSS with $\mathrm{pN} 0$ vs. $\mathrm{pNx}$ patients $(81.2 \%$ vs. $77.8 \%$ ). They did concede that a lack of standardized criteria for LND selection was a possible explanation for the lack of difference (50). Mason et al. studied 1,029 patients who underwent $\mathrm{NU}+/-\mathrm{LND}$ and found no survival difference between $\mathrm{pN} 0$ and $\mathrm{pNx}$ patients; however, only a small proportion $(\mathrm{n}=276)$ were $+\mathrm{LND}(51)$. Inokuchi et al. retrospectively reviewed a multi-institutional cohort of 2,037 patients and found poorer OS with $\mathrm{pN}+$ patients (estimated 5-year OS 30\%); however, on multivariable analysis no improvement in CSS or OS was seen with LND, (median LNY =6) (56). It should be noted that in these studies, the authors largely compared $\mathrm{pNx}$ to $\mathrm{pN} 0$, with few $\mathrm{pN}+$ patients, which may explain the lack of improvement in survival outcomes for LND.

In 2018, Guo et al. published an extensive systematic review and meta-analysis, the first meta-analysis on this subject, of 11 studies and 7,516 patients. They found no difference in hazard ratio (HR) between +LND and nonLND (NLND) groups, as well as no difference in CSS between $\mathrm{pN} 0$ and $\mathrm{pNx}$ patients. Even with subgroup analysis, no difference in RFS for LND or NLND $\geq$ pT2 patients. However, improved CSS (HR $=3.38)$ was seen when comparing $\mathrm{pN} 0$ to $\mathrm{pN}+$ patients. Based on these results, the authors concluded that LND does allow for more accurate staging and survival prediction, but its independent impact on survival remained unclear (57). Indeed, while the EAU guidelines on UTUC agree that LND allows for improved staging of UTUC, they recommend against LND in superficial UTUC (pTa/ 
Table 2 Lymph node drainage/dissection templates

\begin{tabular}{|c|c|c|c|c|c|c|c|}
\hline \multirow{2}{*}{ Study } & \multicolumn{6}{|c|}{ Lymph node drainage/template (based on primary tumor site) } & \multirow{2}{*}{ Outcomes } \\
\hline & Renal pelvis & Upper/mid ureter & Distal ureter & Renal pelvis & per/mid ureter & Distal ureter & \\
\hline Kondo $2007^{\star}(41)$ & $\mathrm{H}, \mathrm{PC}, \mathrm{RC}$ & $\mathrm{RC}, \mathrm{IAC}$ & $\mathrm{Cl}, \mathrm{O}$ & $\mathrm{H}, \mathrm{PA}, \mathrm{IAC}$ & PA & $\mathrm{Cl}, \mathrm{II}$ & \\
\hline Kondo 2014 (42) & $\mathrm{H}, \mathrm{PC}, \mathrm{RC}, \mathrm{IAC}$ & $\mathrm{H}, \mathrm{PC}, \mathrm{RC}, \mathrm{IAC}$ & - & $\mathrm{H}, \mathrm{PA}$ & $\mathrm{H}, \mathrm{PA}$ & - & $\begin{array}{c}\text { 2- \& 5-year RFS = } \\
87 \% \text { \& } 84 \% \\
\text { 2- \& 5-year CSS = } \\
95 \% \text { \& } 91 \% \\
\text { Decreased regional } \\
\text { node recurrence }\end{array}$ \\
\hline Matin $2015^{\star}(44)$ & $\mathrm{H}, \mathrm{PC}, \mathrm{RC}, \mathrm{IAC}$ & $\mathrm{H}, \mathrm{PC}, \mathrm{RC}^{\star *}$ & PC, pelvic LN & $\mathrm{H}, \mathrm{PA}$ & $\begin{array}{c}\mathrm{H}, \mathrm{PA}^{\star \star} \\
\mathrm{PA}, \mathrm{Cl}, \mathrm{II}^{\star \star \star}\end{array}$ & PA, Cl, El, II & - \\
\hline
\end{tabular}

${ }^{*}$, this study only reported lymph node metastatic drainage patterns; ${ }^{* \star}$, for upper ureteral tumors; ${ }^{* *}$ for mid ureteral tumors. $\mathrm{H}$, hilar lymph nodes; PC, paracaval lymph nodes; RC, retrocaval lymph nodes; IAC, interaortocaval lymph nodes; PA, para-aortic lymph nodes; $\mathrm{Cl}$, common iliac lymph nodes; II, internal iliac lymph nodes; El, external iliac lymph nodes; O, obturator lymph nodes; PS, presacral lymph nodes; RFS, recurrence-free survival; CSS, cancer-specific survival; LND, lymph node dissection.

T1) and provide a grade $\mathrm{C}$ recommendation for LND in invasive ( $\geq$ pT2) UTUC (27). A prospective RCT would assist in elucidating the impact of LND on survival in patients with UTUC, if any.

\section{Adrenal management}

Adrenal metastasis of UTUC is exceedingly uncommon; in an analysis of LNU outcomes, only one adrenal metastasis was reported in a cohort of 116 patients (60). In the past three decades there has been only one study assessing the utility of adrenalectomy at time of NU for UTUC. Huang et al. reported on 110 patients who underwent NU for UTUC, of which 40 had concurrent ipsilateral adrenalectomy at the time of NU (based on surgeon preference). No adrenal metastases were reported in the adrenalectomy cohort on pathologic analysis at time of surgery. In the entire cohort of 110,10 patients developed distant metastases (5 in adrenalectomy and 5 in adrenal sparing) and none were located in the adrenal gland or adrenal fossa (61). If pre-operative imaging demonstrates adrenal involvement, or the adrenal appears abnormal intraoperatively, adrenalectomy should be performed, otherwise ipsilateral adrenalectomy at time of NU likely can be safely omitted; however, we lack level 1 evidence supporting this practice.

\section{Vena cava thrombus management}

Similar to metastatic adrenal metastatic spread, UTUC is rarely associated with a vena cava thrombus; fewer than 50 cases are reported in the literature, largely consisting of case reports owing to its rarity. Li et al. published a case report of their experience but included a literature review of the topic of studies from 1972 to 2016. They reviewed 48 cases of UTUC with vena cava thrombus; 22 patients died dead (ranging from death immediately after surgery to alive for 60 months), 14 with no evidence of disease, and 14 with no recorded followup (62). Similarly, Singh et al. reported a case report and literature review, reporting that the prognosis of UTUC with caval thrombi was poorer than with renal 

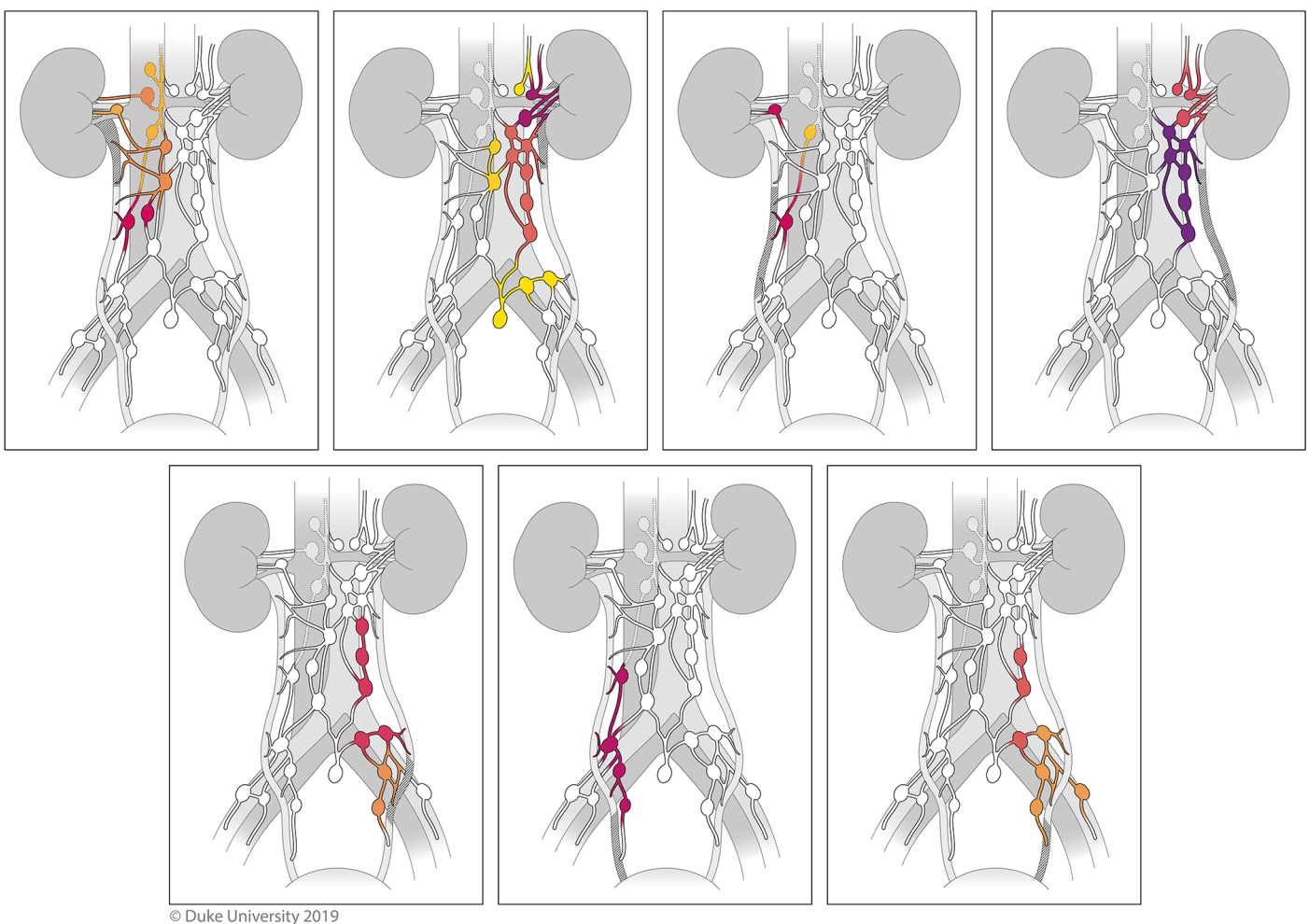

Figure 5 The lymphatic drainage patterns for UTUC. (A) Drainage of the right renal pelvis (paracaval > hilar $>$ interaortocaval > retrocaval); (B) drainage of the left renal pelvis (hilar > para-aortic > interaortocaval > other); (C) drainage of the right proximal ureter (hilar = paracaval > retrocaval); (D) drainage of the left proximal ureter (para-aortic > hilar); (E) drainage of the left mid ureter (para-aortic > hilar); (F) drainage of the right distal ureter (pelvic); (G) drainage of the left distal ureter (pelvic).

cell carcinoma; $>50 \%$ of patients with UTUC associated caval thrombi were dead within a year of surgery (63). The surgical management does not differ based on UTUC versus renal cell carcinoma primary; however, the paucity of cases restricts extensive review of various surgical techniques (64-68). Variant histology is not common, but when present, sarcomatoid differentiation is most commonly seen, although it is less common in general (69-71).

\section{Ureter management}

A grade A recommendation from the EAU for diagnostic workup for UTUC consists of cystoscopy, urine cytology, and CT urography. However, diagnostic ureteroscopy (URS) only receives a grade C recommendation (27). With URS and UTUC, concerns arise regarding the risk of tumor recurrence and/or urothelial cancer cell seeding elsewhere in the urinary tract, as well as the risk of URS delaying NU and negatively affecting outcomes.
Recently, three systematic review and meta-analyses have been conducted to study the effect of pre-operative URS on oncologic outcomes following NU. Tan et al., Guo et al., and Liu et al. reviewed 11, 8, and 9 high quality studies, respectively, all of which retrospectively reviewed ureteroscopic impact on IVRS, CSS, metastasis-free survival (MFS), and OS following NU. In all three reviews, URS was negatively associated with IVRS (HR 1.42-1.81) by roughly $40-80 \%$. URS did not significantly impact MFS or OS, and with Tan and Liu, URS also did not affect CSS (72-74). Interestingly, Guo reported an increased CSS with URS pre-operatively (HR 0.76), but felt that this was due to selection bias, as patients with more advanced disease (and therefore poorer prognoses) would have a less equivocal diagnostic workup and would proceed directly to NU (72).

Although these reviews found largely no URS impact on oncologic outcomes, with the exception of IVRS, no mention was made of the timing of the procedures. Urothelial cancer, especially high grade or invasive, should 

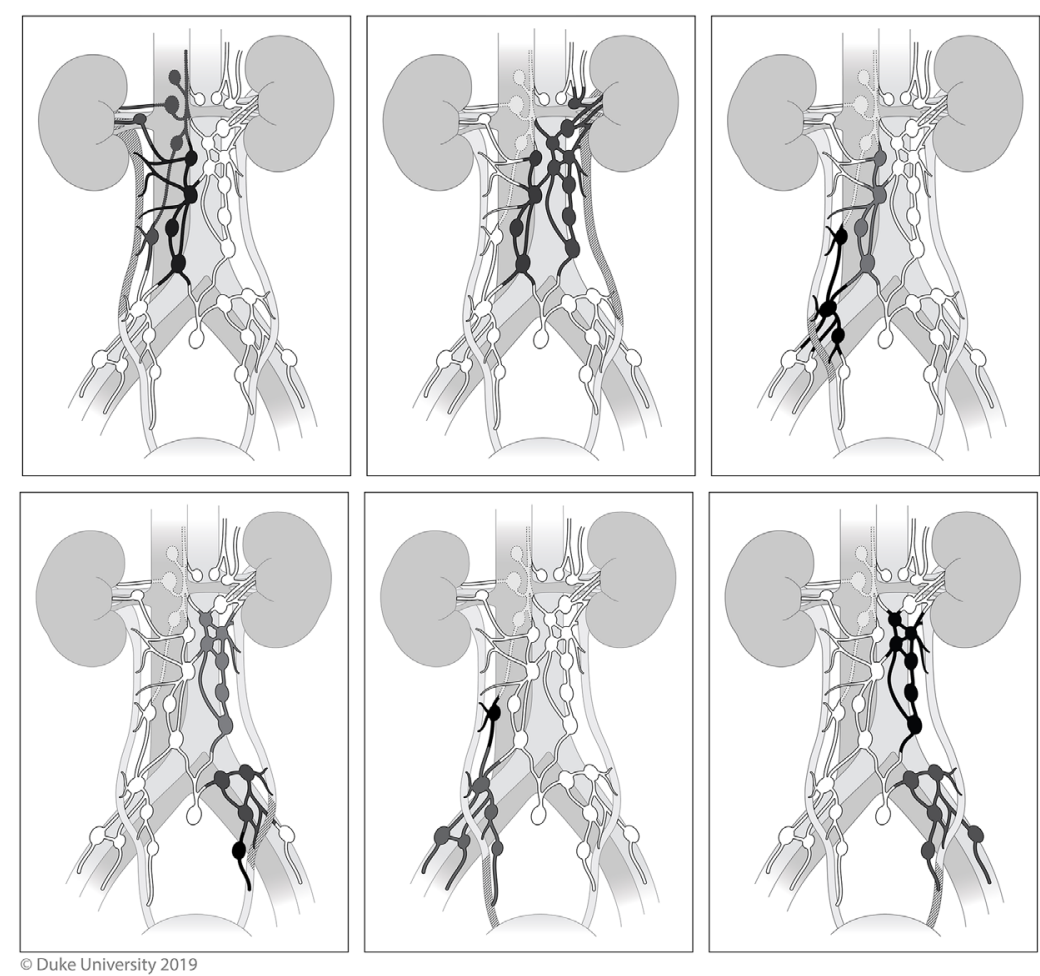

Figure 6 Proposed lymph node dissection templates. (A) Dissection template for right renal pelvis and proximal ureteral tumors; (B) dissection template for left renal pelvis and proximal ureteral tumors; (C) dissection template for right mid ureteral tumors; (D) dissection template for left mid ureteral tumors; (E) dissection template for right distal ureteral tumors; (F) dissection template for left distal ureteral tumors.

be treated in the most reasonably expeditious fashion, which may not always be possible for a number of reasons, such as the ability of the health care system to provide care (e.g., surgeon schedule, access to appropriate specialist, OR availability) or the desire to give neoadjuvant chemotherapy (NAC) [especially if adjuvant chemotherapy (AC) may not be possible]. To this end, Boorjian et al., Sundi et al. and $\mathrm{Xia}$, et al. studied the impact of delay of NU due to URS on oncologic outcomes (75-77).

Boorjian stratified patients by NU alone ( $n=34)$, URS for biopsy followed by NU ( $n=75)$, and URS followed by ablation and ultimately NU $(n=12)$. Mean time to from URS and biopsy to NU was 28 days, and from ablation to NU was 196 days. CSS, MFS, or OS did not differ among the groups (75). As the decision for timing was surgeondependent, this may support the notion that if deemed appropriate by the surgeon, superficial/low grade UTUC can safely be managed in a staged manner.

Sundi stratified patients by "early" and "delayed" treatment following URS. Early $(\mathrm{n}=186)$ and delayed $(\mathrm{n}=54)$ were defined by $<3$ or $>3$ months between URS and extirpative surgery. Reasons for delay included administration of NAC $(n=27)$ or surveillance $(n=9)$. There was no difference in CSS or OS if surgery was delayed following URS (76). Even with subgroup analysis that removed NAC patients, CSS and OS were not affected by delay $>3$ months. It should be noted that the median time to surgery in the delayed group was not reported and the authors concluded that this demonstrated it was safe to delay surgery for NAC; no conclusions should be drawn regarding safety of long-term delay of NU or ureterectomy.

Fortunately, Xia et al. stratified patients six groups based on timing between URS and NU: $\leq 7,8-30,31-60$, 61-90, 91-120, and 121-180 days. With the exception of the longest delay group, 121-180 days, timing was not associated with OS. However, patients delayed 121-180 days did have poorer OS compared to a wait time of 8-30 days (HR 1.61). Patients in the 121-180-day group were older, more likely to be treated at academic centers, and more likely to have $\geq$ pT2 disease. However, a similar poorer OS 
Table 3 LND outcomes

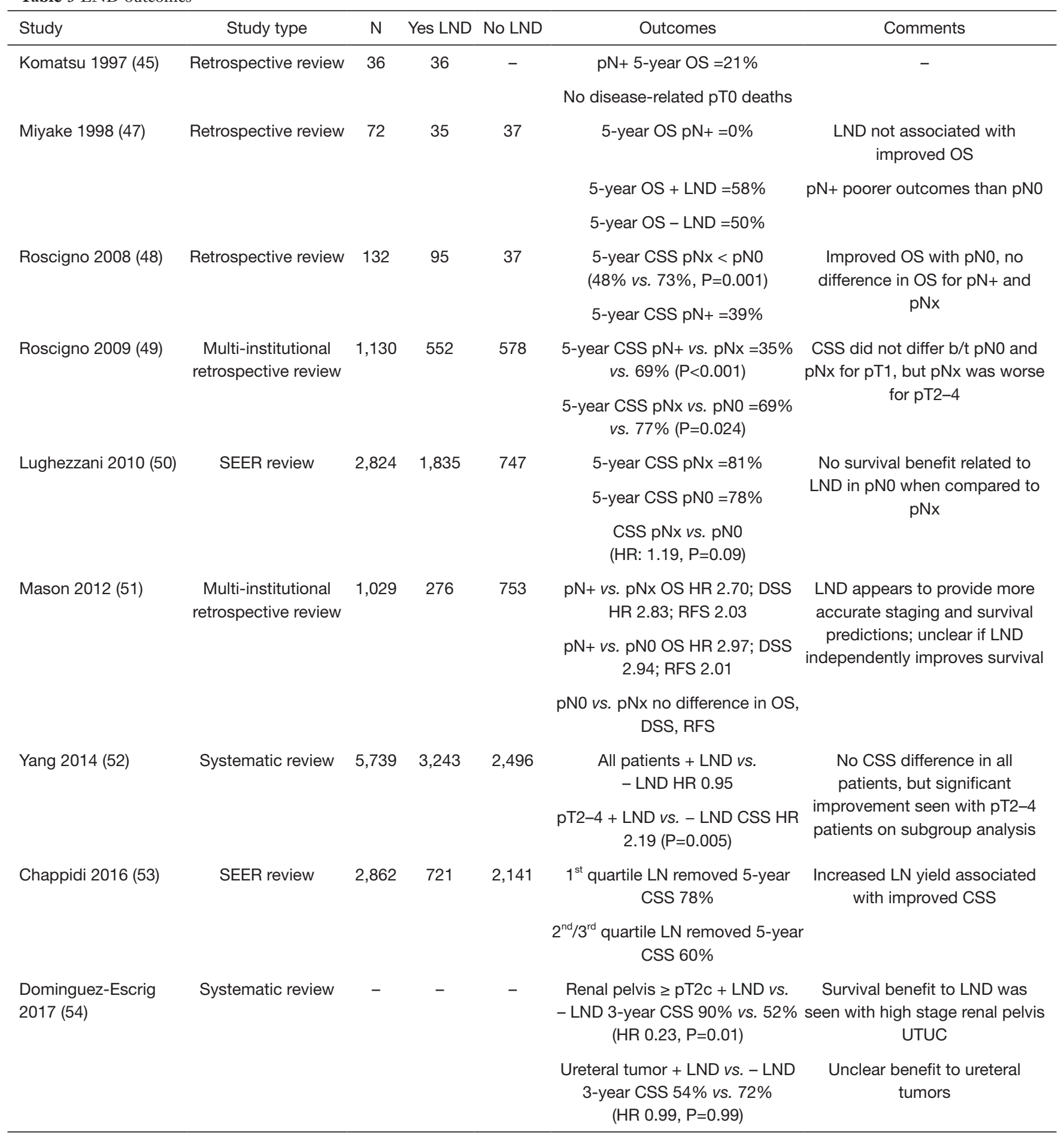

Table 3 (continued) 
Table 3 (continued)

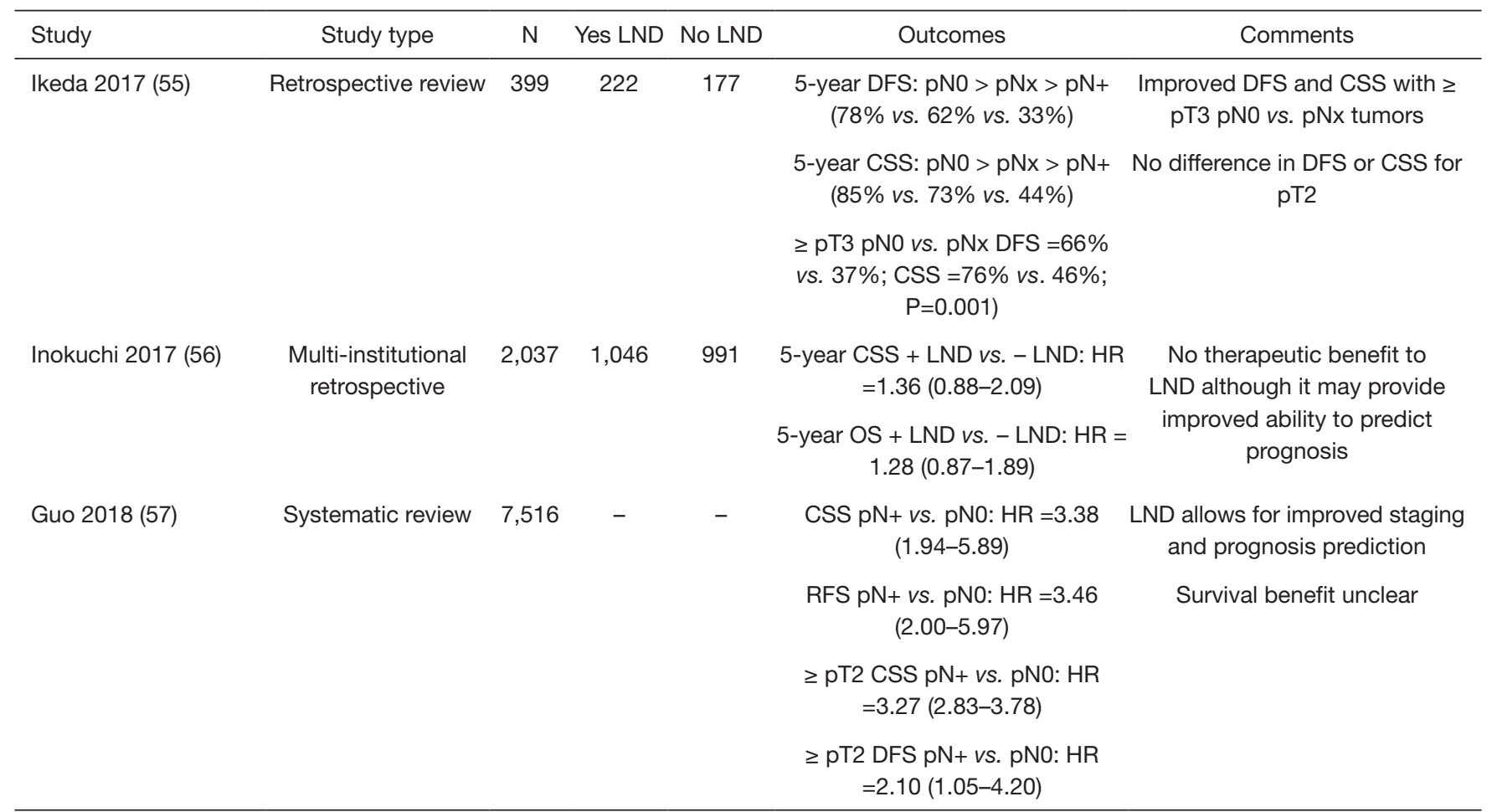

LND, lymph node dissection; OS, overall survival; CSS, cancer-specific survival; SEER, Surveillance, Epidemiology and End Results; HR, hazard ratio; RFS, recurrence-free survival; DSS, disease-specific survival; LN, lymph node; UTUC, upper tract urothelial carcinoma; DFS, disease-free survival.

also seen on subgroup analysis with higher risk patients (HR 1.56) (77).

The practicing urologist should be aware that URS before NU increases IVR rates but otherwise does not negatively impact CSS, MFS, or OS. Additionally, although the available evidence is all retrospective in nature, reasonable delays in surgery (i.e., <121 days) do not seem to negatively affect oncologic outcomes. There is a need for prospective data in all respects regarding URS and $\mathrm{NU}$, especially focusing on interventions to decrease IVR, perhaps studying the impact of prophylactic perioperative intravesical chemotherapy.

\section{Intravesical chemotherapy}

Urothelial carcinoma has a propensity to recur, regardless of initial location in the urinary tract. Reported bladder recurrence rates following NU range from 15-50\% (78-80). The field change and intraluminal seeding hypotheses are the two leading hypotheses for mechanism of recurrence, although with new data the intraluminal seeding is becoming more prevalent (81). The field change hypothesis proposes that the urothelium is broadly exposed to carcinogens or there is/are inherent mutations and/or defects in the urothelium and multifocal tumors recur from independent clones of altered cells $(82,83)$. Intraluminal seeding proposes that recurrent urothelial tumors are clones of the initial altered cell, and recurrences arise from intraluminal tumor cell spread (83-86). If this is the mechanism by which recurrence occurs, then it follows that intravesical chemotherapy may be effective in preventing recurrence (87).

The use of intravesical chemotherapy to prevent bladder recurrences following NU for UTUC was first reported by Tari et al. in 1987, who administered a variety of intravesical chemotherapeutic agents [mitomycin C (MMC), carboquone/cytosine arabinoside, or adriamycin] for 2 years post-operatively; only two patients suffered a bladder recurrence during that time (88). However, the use of a single post-operative dose of intravesical chemotherapy was not reported in a prospective fashion until Sakamoto et al. in 2001, who reported on 25 patients receiving MMC 
$20 \mathrm{mg}$ plus cytosine arabinoside (89). Multiple systematic reviews and meta-analyses have all shown that a single dose of prophylactic intravesical chemotherapy post-operatively is associated with a $~ 50 \%$ decrease in IVR $(81,90,91)$.

Despite the above, it was only recently, in 2015, that the EAU released an update to the UTUC guidelines, giving a grade B recommendation to administer a single dose of post-operative chemotherapy following NU (27). This recommendation based on two RCTs that showed a $52 \%$ decreased risk of bladder recurrence with an absolute risk reduction (ARR) in bladder recurrence of $13 \%$, following instillation of a single dose of intravesical chemotherapy within 10 days of NU (81,92-94).

The ODMIT-C trial was the first RCT to explore the effect of intravesical chemotherapy on post NU IVR. Two hundred and eighty-four patients undergoing NU for UTUC were randomized to standard post-operative care, or to receive a single dose of post-operative intravesical MMC. The primary end point was incidence of bladder cancer in the first 12 months following NU. In the final intention to treat analysis, 21 of 120 patients (18\%) who received post-op MMC, while 32 of 119 patients (27\%) who did not receive post-op MMC had a bladder recurrence in the first 12 months $(\mathrm{P}=0.055)$. However, on treatment as per protocol analysis, $16 \%$ of MMC receiving patients and $27 \%$ of control patients suffered a bladder recurrence in the first 12 months $(\mathrm{P}=0.03)$. They calculated an ARR of $11 \%$ and relative risk reduction (RRR) of $40 \%$, and a number needed to treat (NNT) of 9 (93).

Ito et al. performed a similar trial in 2013 , investigating the effect of post-operative intravesical chemotherapy on bladder recurrences following NU. In contrast to the ODMIT-C study, they used intravesical pirarubicin instead of MMC, and specified that intravesical chemotherapy was to be instilled within 48 hours postoperatively. They also found decreased incidence of IVRs with intravesical chemotherapy, noting a HR of 0.26 (92). This was a phase II trial investigating the use of pirarubicin; the study group is, as of this writing, currently recruiting for a phase III trial investigating its use (95).

However, despite level 1 evidence, a growing body of retrospective data, and governing body recommendations for post-operative intravesical chemotherapy following NU, many urologists still do not administer perioperative intravesical chemotherapy. A recent survey of urologists who routinely perform NU in the USA showed that only $\sim 51 \%$ administer post-op intravesical chemotherapy (87). Commonly cited reasons for not administering it were lack of evidence to support its use (the most frequently cited reason), concerns regarding patient morbidity and toxicity, and office infrastructure not conducive to its use.

Additionally, some urologists suspect the timing of intravesical chemotherapy is important. Both ODMIT-C and Ito's trial administered post-operative intravesical chemotherapy due to concerns about spillage into the operative field. Some theorize that intra-operative intravesical chemotherapy is superior, and Moriarty et al. demonstrated that intra-operative intravesical chemotherapy was safe to administer. In their study, MMC was instilled at the start of the surgery and then drained just before the bladder cuff was resected, with no major ( $\geq$ Clavien grade 3) complications noted (96). A small retrospective review comparing intra-operative to post-operative intravesical chemotherapy by Noennig et al. found that intra-operative chemotherapy (MMC instilled at the start of surgery and drained just before the distal ureterectomy) had superior IVRS compared to post-operative (HR 0.113) (97). Currently, a phase II trial studying the timing of intravesical MMC is enrolling (NCT03658304).

\section{Chemotherapy}

Although there is good evidence supporting the use of cisplatin-based NAC in muscle-invasive urothelial carcinoma of the bladder (UCB), similar evidence for perioperative chemotherapy (PC) with either NAC or AC in UTUC is lacking $(98,99)$. Due to limited number of studies examining this subject, and the lack of level 1 evidence, there are no EAU, AUA, or the National Comprehensive Cancer Network (NCCN) guidelines regarding the use of PC with UTUC.

The available literature is mixed regarding the efficacy of PC. Several large studies noted no impact of PC on survival outcomes $(100,101)$. These findings were contraindicated in other retrospective reviews published around the same time (102-105). More recently, a greater proportion retrospective studies are suggesting a survival benefit with the use of PC, including a number of systematic reviews and meta-analyses (106-115). However, this is contradicted by Necchi et al. who, in 2018, published findings from a multicenter retrospective review of 1,544 patients, and noted no improvement in survival with AC for UTUC (116).

Use of PC has increased with time. In an National Cancer Database (NCDB) review, Gin et al. reported that the use of PC with UTUC had increased from $9.6 \%$ to $13.8 \%$ from 2004 to 2013 , with the increase largely due to 
Table 4 UTUC risk factors for risk stratification (110)

\begin{tabular}{l} 
Risk factor (low risk $=0$; intermediate risk $=1-2$; high risk group $\geq 3$ ) \\
\hline $\mathrm{pT} 3$ \\
$\mathrm{pN}+$ \\
Grade 3 \\
LVI present \\
Positive soft tissue surgical margin
\end{tabular}

UTUC, upper tract urothelial carcinoma; LVI, Iymphovascular invasion.

an increase in NAC administration $(0.7 \%$ to $2.1 \%)$, as $\mathrm{AC}$ administration remained stable $(\sim 11 \%)(117)$. No mention was made of the type of PC administered in that study, but Cohen $e t a l$. published a similar study utilizing SEERMedicare data from 2002 to 2011 with similar findings: $13.6 \%$ PC administration rate of which $1.8 \%$ was NAC and $11.8 \%$ AC (118). In this analysis, carboplatin/gemcitabine was most frequently used (42\%), followed by gemcitabine/ cisplatin (G/C) (22\%), carboplatin/paclitaxel (16\%), with methotrexate/vinblastine/doxorubicin/cisplatin (MVAC) used the least $(<4 \%)$.

As there are limited data in general regarding the efficacy of PC for UTUC, similarly there are a paucity of data to direct use as to which type of PC is optimal. Guidelines for muscle-invasive bladder cancer (MIBC) generally recommend platinum-based regimens (cisplatin or carboplatin), with cisplatin recommended for NAC, and these guidelines help inform use in UTUC (99). Historically, MVAC was the predominant AC regimen, but after 2008, G/C and other chemotherapy regimens began to take greater prominence (113). Although sparse, some data support MVAC over other regimens. Ikeda et al. found improved 5-year CSS for high risk patients (e.g., $\geq 3$ risk factors) with the use of AC with MVAC when compared to either AC with G/C or no AC. Risk factors to stratify risk status are listed in Table 4. Importantly, CSS benefit was not seen with G/C for AC, nor with any AC for low or intermediate risk disease (110). Shirotake et al. also found improved RFS and CSS for high risk patients receiving MVAC for AC, while those receiving $\mathrm{G} / \mathrm{C}$ or no AC did not show a benefit (104). All other studies noting a benefit to PC did not report data supporting one chemotherapy regimen compared to another. The majority of studies utilized platinum-based chemotherapy, and cisplatin-based in renal function allowed; carboplatin was largely reserved for patients unable to tolerate cisplatin $(102,103,105,108,109,112)$.

It is unclear if there is benefit with NAC, AC, or both. Those in favor of NAC argue that that it can treat micrometastatic disease, ideally lead to pathologic downstaging and/or complete pathologic response, and patients may no longer be candidates for cisplatin-based therapy following NU $(101,106)$. In fact, Yafi et al. reported in a cohort of 1,029 patients, $49 \%$ were cisplatin-eligible preoperatively, but only $18 \%$ post-operatively (101). However, opponents argue that UTUC and UCB may respond differently chemotherapy as there are notable cellular and DNA differences between the two, and as such data for UCB cannot be extrapolated to UTUC $(102,107)$. Furthermore, accurate staging is notoriously more difficult for UTUC and as such NAC administration may lead to over treatment of patients who may not benefit from it (107). Proponents of AC argue that appropriate patient selection is aided by having pathology, thus low stage patients can avoid unnecessary chemotherapy (107).

In an NCDB review of 6,174 patients, Almassi et al. found that pathologic response significantly increased with NAC [odds ratio (OR) 19.8] (106). Similar improvements in pathologic response ( 14\%) with NAC were noted by Aziz et al. in a systematic review and meta-analysis (107). Kim et al. recently published a systematic review and meta-analysis of 4 trials $(n=318)$ studying the impact of NAC on survival outcomes, finding that NAC was associated with absolute improvements of $13 \%, 18 \%$, and $11 \%$ for progression-free survival (PFS), CSS, and OS, respectively, when compared to no NAC (111). Interestingly, Hosogoe et al. showed a survival benefit with NAC in clinical node positive patients for PFS (HR 0.32), CSS (HR 0.34), and OS (HR 0.39) (109). Smaller studies also showed survival benefit to NAC $(103,112)$. These are detailed in Table 5.

The use of AC in UTUC has been studied to a greater extent than NAC; a systematic review and meta-analysis by Gregg et al. reviewed 13 studies $(\mathrm{n}=4,642)$, of which 11 focused on $\mathrm{AC}$, and found an improvement in OS (HR 0.75), DFS (HR 0.54), and CSS (HR 0.69) with PC (108). Similar findings were demonstrated in a systematic review and meta-analysis by Leow et al., finding cisplatinbased AC associated with improved OS (HR 0.43), DFS (HR 0.49), but not CSS (102). In an NCDB review of 3,252 patients, Seisen et al. also noted improvement in OS with AC (median survival 41.41 vs. 35.78 months, $\mathrm{P}<0.001)$ (115). Similar improvement in survival outcomes with the use of AC was also seen in individual studies 
Table 5 Outcomes of NAC for UTUC

\begin{tabular}{|c|c|c|c|c|}
\hline Study & $\mathrm{N}$ & NAC (n) & Regimen [n] & Outcomes \\
\hline \multirow{2}{*}{ Rajput 2011 (119) } & & & [4], GTA [4], IAG [2], GC [2], GT [2] & No diff in EBL, transfusion rate, LOS \\
\hline & & & & No diff in periop complication rate \\
\hline Leow* 2014 (102) & 1,782 & 154 & MVAC, GC, CGI, other & NAC with DFS: HR $0.41(0.22-0.76)$ \\
\hline Porten 2014 (103) & & & & NAC 5-year OS $=80 \%$ vs. no NAC 58\%, P=0.0015 \\
\hline \multirow[t]{3}{*}{ Kubota 2017 (112) } & 234 & 101 & GCarbo [76], GC [21], other [4] & NAC on IVRS: $\mathrm{HR}=0.52, \mathrm{P}=0.023$ \\
\hline & & & & NAC on RFS: $\mathrm{HR}=0.57, \mathrm{P}=0.021$ \\
\hline & & & & NAC on OS: $\mathrm{HR}=0.62, \mathrm{P}=0.081$ \\
\hline Almassi 2018 (106) & & & & NAC on PR: OR 19.8 (11.8-33.5) \\
\hline \multirow[t]{3}{*}{ Hosogoe 2018 (109) } & 233 & 55 & GC or GCarbo & 5-year PFS NAC vs. no NAC: $60 \%$ vs. $39 \%, P=0.018$ \\
\hline & & & & 5-year CSS NAC vs. no NAC: $71 \%$ vs. $54 \%, P=0.015$ \\
\hline & & & & 5 -year OS NAC vs. no NAC: $65 \%$ vs. $50 \%, P=0.032$ \\
\hline \multirow[t]{2}{*}{$\mathrm{Kim}^{\star} 2019(111)$} & 318 & - & GC, GCarbo, MVAC, other & $\begin{array}{l}\text { NAC relative improvement in PFS, CSS, and OS: } 45 \% \text {, } \\
59 \%, 57 \%\end{array}$ \\
\hline & & & & NAC effect on downstaging: $O R=0.21(0.27-0.57)$ \\
\hline
\end{tabular}

*, denotes systematic review/meta-analysis. NAC, neoadjuvant chemotherapy; UTUC, upper tract urothelial carcinoma; MVAC, methotrexate, vinblastine, adriamycin, cisplatin; CGI, cisplatin, gemcitabine, ifosfamide; GTA, gemcitabine, paclitaxel, doxorubicin; IAG, ifosfamide, doxorubicin, gemcitabine; GC, gemcitabine, cisplatin; GT, gemcitabine, paclitaxel; GCarbo, gemcitabine, carboplatin; LND, lymph node dissection; EBL, estimated blood loss; LOS, length of stay; DFS, disease-free survival; HR, hazard ratio; DSS, diseasespecific survival; IVRS, intravesical recurrence free survival; PR, pathologic response; OR, odds ratio; PFS, progression-free survival.

$(104,105,110,113)$. Even in metastatic UTUC, Seisen et al. demonstrated improvement in 3-year OS with the use of PC and NU when compared to just chemotherapy (16.2\% vs. 6.4\%; $\mathrm{P}<0.001)(120)$. However, unlike NAC, there are studies that show no benefit with the use of AC. The largest of these is a recent retrospective review by Necchi et al. which reviewed 1,544 patients, 312 of whom received AC ( $75 \%$ cisplatin-based), and found no difference with $\mathrm{OS}$ for patients receiving $\mathrm{AC}$ and those who didn't (116). Another large review by Yafi et al. of 1,029 patients also found no association with improved OS or CSS with the use of AC (101). These studies are displayed in Table 6.

Recently, level 1 evidence has been presented in abstract form. The POUT trial, a prospective, RCT studying the impact of PC on survival outcomes (specifically PFS), was recently presented and was notable for finding a significant improvement in PFS with PFS (HR 0.47) with the use of PC (cisplatin-based unless contraindicated, at which point a carboplatin-based regimen was provided) (121). Recruitment was halted early due to the significant PFS improvement seen with the AC arm. Although the official paper has yet to be published, the results of POUT are the strongest level 1 evidence supporting PC with UTUC. However, it is not without its limitations. Inclusion criteria were surgically staged pT2-4 and N0-3, or pT1 and $\mathrm{N}_{+}$, and who were fit for AC. As such, all patients who were chemotherapy-ineligible were excluded, leading to significant selection bias for only healthy patients. Notably, although statistically underpowered to evaluate, there still was a survival benefit of the carboplatin subset of patients; a similar survival benefit of carboplatin in UCB is not seen. Although promising results, POUT still leaves questions unanswered. 
Table 6 Outcomes of AC for UTUC

\begin{tabular}{|c|c|c|c|c|c|}
\hline Study & $\mathrm{N}$ & $\mathrm{AC}[\mathrm{n}]$ & Regimen & Outcomes & Comment \\
\hline $\begin{array}{l}\text { Hellenthal } \\
2009(97)\end{array}$ & 542 & 121 & $\begin{array}{l}\text { MVAC [65], GC [22], } \\
\text { other [23] }\end{array}$ & OS with AC: HR =1.06 (0.80-1.40) & $\begin{array}{l}\text { AC not associated with } \\
\text { improved CSS or OS }\end{array}$ \\
\hline $\begin{array}{l}\text { Leow}^{*} 2014 \\
(99)\end{array}$ & 1,782 & 482 & - & OS with AC (cisplatin-based): HR $=0.43(0.21-0.89)$ & $\begin{array}{l}\text { Cisplatin-based AC } \\
\text { associated with improved } \\
\text { DFS, OS }\end{array}$ \\
\hline \multirow{2}{*}{$\begin{array}{l}\text { Yafi } 2014 \\
(98)\end{array}$} & \multirow[t]{2}{*}{1,029} & & \multirow[t]{2}{*}{-} & AC on CSS: HR $=0.775(0.401-1.496)$ & \multirow{2}{*}{$\begin{array}{l}\text { AC did not improve OS or } \\
\text { CSS }\end{array}$} \\
\hline & & & & AC on OS: HR $=0.695(0.290-1.663)$ & \\
\hline $\begin{array}{l}\text { Fujita } 2015 \\
(102)\end{array}$ & 74 & 45 & GC, GCarbo & 5-year RFS AC vs. no AC: $34 \%$ vs. $14 \%(P=0.014)$ & $\begin{array}{l}\text { AC associated with improved } \\
\text { CSS for } \mathrm{pN}+\text { patients }\end{array}$ \\
\hline \multirow{3}{*}{$\begin{array}{l}\text { Shirotake } \\
2015(101)\end{array}$} & \multirow[t]{3}{*}{873} & \multirow[t]{3}{*}{129} & \multirow[t]{3}{*}{ MVAC, GC } & MVAC 1-year \& 2-year RFS: $71 \%$ \& 48\% & \multirow{3}{*}{$\begin{array}{l}\text { MVAC associated with } \\
\text { improved RFS over GC or no } \\
\text { AC }\end{array}$} \\
\hline & & & & GC 1-year \& 2-year RFS: 48\% \& NR & \\
\hline & & & & No AC 1-year \& 2-year RFS: 53\% \& 40\% & \\
\hline $\begin{array}{l}\text { Aziz } 2017 \\
(104)\end{array}$ & 2,131 & 694 & $\begin{array}{l}\text { MVAC, MEC, MVEC, } \\
\text { GC, other }\end{array}$ & - & $\begin{array}{l}\text { Meta-analysis not performed, } \\
\text { but review shows associated } \\
\text { with AC and CSS and OS }\end{array}$ \\
\hline \multirow[t]{2}{*}{$\begin{array}{l}\text { Nakagawa } \\
2017(110)\end{array}$} & \multirow[t]{2}{*}{109} & \multirow[t]{2}{*}{43} & \multirow[t]{2}{*}{ MVAC, GC } & $\begin{array}{l}\text { Multivariate analysis: } \mathrm{AC} \text { on RFS: } \mathrm{HR}=0.41 \text {, } \\
\mathrm{P}=0.0178\end{array}$ & \multirow{2}{*}{$\begin{array}{l}\text { AC associated with improved } \\
\text { RFS and CSS with pT3-4 } \\
\text { UTUC }\end{array}$} \\
\hline & & & & AC on CSS: $\mathrm{HR}=0.33, P=0.0375$ & \\
\hline $\begin{array}{l}\text { Necchi } 2018 \\
(113)\end{array}$ & 1,544 & 312 & $\begin{array}{l}\text { Cisplatin-based [148], } \\
\text { carboplatin-based [27], } \\
\text { non-platinum-based } \\
\text { [22], not reported [115] }\end{array}$ & AC on OS: HR =1.14 (0.91-1.43) & $\begin{array}{l}\text { AC did not improve OS } \\
\text { compared with observation }\end{array}$ \\
\hline
\end{tabular}

*, denotes systematic review. AC, adjuvant chemotherapy; MVAC, methotrexate, vinblastine, Adriamycin, cisplatin; CSS, cancer-specific survival; HR, hazard ratio; OS, overall survival; DFS, disease-free survival; RFS, recurrence-free survival; GC, gemcitabine, cisplatin; GCarbo, gemcitabine, carboplatin; NR, not reached; MEC, methotrexate, etoposide, cisplatin; MVEC, methotrexate, vinblastine, epirubicin, cisplatin; UTUC, upper tract urothelial carcinoma.

The efficacy of PC with NU remains unclear. Prospective RCTs are needed with appropriate inclusion and exclusion criteria, with an intention to treat analysis, especially with a NAC trial.

\section{Outcomes}

The ONU is the gold standard of management for UTUC and has been since its conception nearly 100 years ago (9). However, the advent of the LNU, HALNU, and RANU 
has led to many studies comparing their outcomes.

\section{ONU vs. LNU}

The ONU and LNU have been compared extensively, mostly in retrospective reviews, but some prospective data exist. In a large multi-institutional review of 1,249 cases, Capitanio et al. reported that there was no difference in cancer recurrence and mortality between ONU and LNU (122). However, they conceded that the patients who underwent LNU generally had lower stage tumors and more favorable tumor locations (e.g., renal pelvis) than those receiving ONU. In one of the few prospective randomized trials comparing ONU and LNU, somewhat similar findings were noted. Simone et al. conducted a small randomized prospective study, randomizing 40 patients to ONU and 40 to LNU. They found no difference between IVRS, CSS, and MFS; however, when matched for pT3 disease and high-grade tumors, CSS and MFS was better with ONU versus LNU (11). In a systematic review of 42 studies by Peyronnet et al., poorer CSS and OS were noted with LNU for locally advanced (pT3-4) or highgrade disease, or laparoscopic approach to bladder cuff management (123).

Large systematic reviews and meta-analyses largely show oncologic equivalency between ONU and LNU, with some caveats. Ni et al. published on 21 studies from 2000 to 2011, of which all but one were retrospective in nature, and analysis revealed $9 \%$ improved 5 -year CSS as well as improved IVRS with LNU, but otherwise no difference in 2-year CSS, 5-year RFS, 5-year OS, and metastasis rates (124). Similar to Capitanio et al., $\mathrm{Ni}$ et al. reported that $\mathrm{pTa} / \mathrm{Tis}$ disease was significantly more common in LNU patients compared to ONU. A more recent systematic review and meta-analysis by Liu et al. found equivalent oncologic outcomes between ONU and LNU, regardless of tumor stage or grade (125). Both Liu and Ni found that LNU was associated with a longer operative time, but shorter overall LOS and lower EBL $(124,125)$. Despite that, Liu failed to find a difference in perioperative complications between ONU and LNU. It is important to remember that although LNU allows for a more minimally invasive approach, a larger extraction incision is still required to remove the specimen en bloc.

When the HALNU is also considered, and compared to the LNU and ONU, similar equivalencies are seen. Nouralizadeh et al. performed a systematic review and meta-analysis of 52 studies (19,195 patients) and found no differences between 5-year CSS, OS, and RFS rates among LNU, HALNU, and ONU, as well as no difference between IVRS and metastasis rate. Similar to the systematic reviews and meta-analyses of LNU vs. ONU, LNU was associated with longer operative time when compared to ONU and HALNU, but shorter LOS and EBL (126).

Despite the evidence suggesting that LNU is oncologically equivalent to $\mathrm{ONU}$, concerns still have been raised about its safety. As noted above, some data suggest that for higher grade or stage tumors, or ureteral tumors, LNU may be inferior to ONU (127). Furthermore, early reports raised concerns about port site seeding with LNU (128). However, systematic reviews and meta-analyses have not shown this to be demonstrated in other studies (125).

\section{ONU vs. LNU vs. RANU}

There are a number of studies comparing the three major surgical approaches for NU, but only one RCT. Some data suggest that $\mathrm{ONU}$ tends has a shorter operative time but longer LOS and higher EBL when compared to LNU or RANU (30). However, other studies have found either no difference, or a minimal difference in operative times (e.g., mean difference 10 minutes) $(10,129)$. In an NCDB study of 9,401 patients who underwent NU (3,199 ONU, 2,098 RANU, 4,104 LNU), Rodriguez et al. found that LND is more likely to be performed with RANU (OR 1.51) and less likely in LNU (OR 0.77), but RANU was associated with a lower rate of positive surgical margins when compared to LNU (OR 0.73) (130). Despite the improved margin rate and rate of LND with RANU, use of the robot has been shown to be costlier when compared to LNU $(\$ 23,235$ vs. $\$ 17,637)(14)$. Mullen et al. performed a systematic review of 50 studies comparing outcomes of ONU, LNU, and RANU, finding no difference in operative time among all three approaches, but did note lower EBL and shorter LOS for LNU compared to ONU (10). Mullen does mention that relative to ONU and LNU, there is a paucity of longterm outcomes data for RANU, but what is published shows that RANU appears to have similar efficacy to ONU and LNU. Notably, despite the aforementioned differences, the only RCT performed showed no statistically significant difference in survival outcomes between ONU and LNU, and most other studies also show no differences in survival outcomes among any of the three approaches $(10,30,129,130)$. 


\section{Future developments}

Despite the existence of the NU for over 100 years, there still are many questions to be answered. Prospective data for many of the issues described above are lacking; but that is quickly changing. At time of this publication, the manuscript describing the POUT trial is anxiously awaited. Prospective trials examining timing of perioperative intravesical chemotherapy are being performed to assess both efficacy as well as timing (pre-, intra-, or post-NU). Additionally, exciting developments with immunotherapy, currently specifically with UCB, are rapidly changing the management of bladder cancer and remains an area ripe for study with UTUC. The NU for UTUC has a longstanding history in urology and has evolved throughout the years; the future continues to become the present at a rapidly increasing rate.

\section{Conclusions}

NU is the standard of care for high-grade UTUC. Although some data suggest a survival benefit to PC with $\mathrm{NU}$, there still are data arguing the opposite. Intravesical chemotherapy appears to improve IVRS, but there is still reticence among many Urologists to adopt its use, and trials are underway to elucidate optimal timing and agent use. Limited data support the use of LND for survival benefit, although it does appear that LND improves prognosis. There are LND templates that appear to be beneficial and a complete, templated dissection should be performed. If an LND is planned, the RANU tends to have a higher LNY than the LNU. However, overall there is not a clear consensus of oncologic superiority of a specific surgical approach.

\section{Acknowledgments}

The authors would like to thank Megan Llewellyn for her talented hand with designing the figures in this article.

Funding: None.

\section{Footnote}

Provenance and Peer Review: This article was commissioned by the Guest Editor (Shomik Sengupta) for the series "Surgery for Urologic Cancers" published in Translational Andrology and Urology. The article has undergone external peer review.
Conflicts of Interest: All authors have completed the ICMJE uniform disclosure form (available at http://dx.doi. org/10.21037/tau.2019.12.07). The series "Surgery for Urologic Cancers" was commissioned by the editorial office without any funding or sponsorship. Dr. Tan reports grants from National Cancer Institute - Ruth L. Kirschstein NRSA Institutional Research Training Grant (T32CA093245), outside the submitted work. The authors have no other conflicts of interest to declare.

Ethical Statement: The authors are accountable for all aspects of the work in ensuring that questions relating to the accuracy or integrity of any part of the work are appropriately investigated and resolved.

Open Access Statement: This is an Open Access article distributed in accordance with the Creative Commons Attribution-NonCommercial-NoDerivs 4.0 International License (CC BY-NC-ND 4.0), which permits the noncommercial replication and distribution of the article with the strict proviso that no changes or edits are made and the original work is properly cited (including links to both the formal publication through the relevant DOI and the license). See: https://creativecommons.org/licenses/by-nc-nd/4.0/.

\section{References}

1. Srirangam SJ, van Cleynenbreugel B, van Poppel H. Laparoscopic nephroureterectomy: the distal ureteral dilemma. Adv Urol 2009:316807.

2. Kimball FN, Ferris HW. Papillomatous Tumor of the Renal Pelvis Associated with Similar Tumors of the Ureter and Bladder. Review of Literature and Report of Two Cases. J Urol 1934;31:257-304.

3. Clayman RV, Kavoussi LR, Figenshau RS, et al. Laparoscopic nephroureterectomy: initial clinical case report. J Laparoendosc Surg 1991;1:343-9.

4. Guillonneau B, Jayet C, Tewari A, et al. Robot assisted laparoscopic nephrectomy. J Urol 2001;166:200-1.

5. Pedraza R, Palmer L, Moss V, et al. Bilateral robotic assisted laparoscopic heminephroureterectomy. J Urol 2004;171:2394-5.

6. Nanigian DK, Smith W, Ellison LM. Robot-assisted laparoscopic nephroureterectomy. J Endourol 2006;20:463-5; discussion 45-6.

7. Yates DR, Vaessen C, Roupret M. From Leonardo to da Vinci: the history of robot-assisted surgery in urology. BJU 
Int 2011;108:1708-13; discussion 1714.

8. Ark JTH, Duke S. Open and Laparoscopic Nephroureterectomy. In: Smith J, Howards S, Preminger G, et al. Hinman's Atlas of Urologic Surgery. 4th edition. Elsevier, 2016:82-96.

9. Margulis V, Shariat SF, Matin SF, et al. Outcomes of radical nephroureterectomy: a series from the Upper Tract Urothelial Carcinoma Collaboration. Cancer 2009; 115:1224-33.

10. Mullen E, Ahmed K, Challacombe B. Systematic review of open versus laparoscopic versus robot-assisted nephroureterectomy. Rev Urol 2017;19:32-43.

11. Simone G, Papalia R, Guaglianone S, et al. Laparoscopic versus open nephroureterectomy: perioperative and oncologic outcomes from a randomised prospective study. Eur Urol 2009;56:520-6.

12. Lenis AT, Donin NM, Faiena I, et al. Role of surgical approach on lymph node dissection yield and survival in patients with upper tract urothelial carcinoma. Urol Oncol 2018;36:9.e1-9.e9.

13. Pearce SM, Pariser JJ, Patel SG, et al. The effect of surgical approach on performance of lymphadenectomy and perioperative morbidity for radical nephroureterectomy. Urol Oncol 2016;34:121.e15-21.

14. Stonier T, Simson N, Lee SM, et al. Laparoscopic vs robotic nephroureterectomy: Is it time to re-establish the standard? Evidence from a systematic review. Arab J Urol 2017;15:177-86.

15. Trudeau V, Gandaglia G, Shiffmann J, et al. Robot-assisted versus laparoscopic nephroureterectomy for uppertract urothelial cancer: A population-based assessment of costs and perioperative outcomes. Can Urol Assoc J 2014;8:E695-701.

16. Lee Z, Cadillo-Chavez R, Lee DI, et al. The technique of single stage pure robotic nephroureterectomy. J Endourol 2013;27:189-95.

17. Hemal AK, Stansel I, Babbar P, et al. Roboticassisted nephroureterectomy and bladder cuff excision without intraoperative repositioning. Urology 2011;78:357-64.

18. Patel MN, Aboumohamed A, Hemal A. Does transition from the da Vinci Si to Xi robotic platform impact single-docking technique for robot-assisted laparoscopic nephroureterectomy? BJU Int 2015;116:990-4.

19. Patel MN, Hemal AK. Does Advancing Technology Improve Outcomes? Comparison of the Da Vinci Standard/S/Si to the Xi Robotic Platforms During Robotic Nephroureterectomy. J Endourol 2018;32:133-8.
20. Zargar H, Krishnan J, Autorino R, et al. Robotic nephroureterectomy: a simplified approach requiring no patient repositioning or robot redocking. Eur Urol 2014;66:769-77.

21. Phé V, Cussenot O, Bitker MO, et al. Does the surgical technique for management of the distal ureter influence the outcome after nephroureterectomy? BJU Int 2011;108:130-8.

22. Kang M, Jeong CW, Kwak C, et al. The characteristics of recurrent upper tract urothelial carcinoma after radical nephroureterectomy without bladder cuff excision. Yonsei Med J 2015;56:375-81.

23. Krabbe LM, Westerman ME, Bagrodia A, et al. Surgical management of the distal ureter during radical nephroureterectomy is an independent predictor of oncological outcomes: results of a current series and a review of the literature. Urol Oncol 2014;32:54.e19-26.

24. Ha YS, Chung JW, Choi SH, et al. Impact of a bladder cuff excision during radical nephroureterectomy on cancer specific survival in patients with upper tract urothelial cancer in Korea: a retrospective, multi-institutional study. Minerva Urol Nefrol 2017;69:466-74.

25. Lughezzani G, Sun M, Perrotte P, et al. Should bladder cuff excision remain the standard of care at nephroureterectomy in patients with urothelial carcinoma of the renal pelvis? A population-based study. Eur Urol 2010;57:956-62.

26. Nazzani S, Preisser F, Mazzone E, et al. Nephroureterectomy with or without Bladder Cuff Excision for Localized Urothelial Carcinoma of the Renal Pelvis. Eur Urol Focus 2020;6:298-304.

27. Rouprêt M, Babjuk M, Compérat E, et al. European Association of Urology Guidelines on Upper Urinary Tract Urothelial Cell Carcinoma: 2015 Update. Eur Urol 2015;68:868-79.

28. Laguna MP, de la Rosette JJ. The endoscopic approach to the distal ureter in nephroureterectomy for upper urinary tract tumor. J Urol 2001;166:2017-22.

29. Allard CB, Alamri A, Dason S, et al. The method of bladder cuff excision during laparoscopic radical nephroureterectomy does not affect oncologic outcomes in upper tract urothelial carcinoma. World J Urol 2013;31:175-81.

30. Lee H, Kim HJ, Lee SE, et al. Comparison of oncological and perioperative outcomes of open, laparoscopic, and robotic nephroureterectomy approaches in patients with non-metastatic upper-tract urothelial carcinoma. PLoS One 2019; 14:e0210401. 
31. Li WM, Shen JT, Li CC, et al. Oncologic outcomes following three different approaches to the distal ureter and bladder cuff in nephroureterectomy for primary upper urinary tract urothelial carcinoma. Eur Urol 2010;57:963-9.

32. Luo HL, Kang CH, Chen YT, et al. Oncological impact of endoscopic bladder cuff management during nephroureterectomy varies according to upper urinary tract tumor location. Int J Urol 2014;21:366-9.

33. Pai A, Hussain M, Hindley R, et al. Long-Term Outcomes of Laparoscopic Nephroureterectomy with Transurethral Circumferential Excision of the Ureteral Orifice for Urothelial Carcinoma. J Endourol 2017;31:651-4.

34. Tibi B, Quintens H, Carpentier X, et al. Management of the bladder cuff removal by open excision versus transurethral resection of the ureteral orifice after laparoscopic radical nephroureterectomy in upper urinary tract--urothelial carcinoma. Prog Urol 2014;24:94-101.

35. Walton TJ, Sherwood BT, Parkinson RJ, et al. Comparative outcomes following endoscopic ureteral detachment and formal bladder cuff excision in open nephroureterectomy for upper urinary tract transitional cell carcinoma. J Urol 2009;181:532-9.

36. Xylinas E, Rink M, Cha EK, et al. Impact of distal ureter management on oncologic outcomes following radical nephroureterectomy for upper tract urothelial carcinoma. Eur Urol 2014;65:210-7.

37. Fragkoulis C, Pappas A, Papadopoulos GI, et al. Transurethral resection versus open bladder cuff excision in patients undergoing nephroureterectomy for upper urinary tract carcinoma: Operative and oncological results. Arab J Urol 2017;15:64-7.

38. Kapoor A, Dason S, Allard CB, et al. The impact of method of distal ureter management during radical nephroureterectomy on tumour recurrence. Can Urol Assoc J 2014;8:E845-52.

39. Lee SM, McKay A, Grimes N, et al. Distal Ureter Management During Nephroureterectomy: Evidence from a Systematic Review and Cumulative Analysis. J Endourol 2019;33:263-73.

40. Alvarez-Maestro M, Rivas JG, Gregorio SA, et al. Current role of lymphadenectomy in the upper tract urothelial carcinoma. Cent European J Urol 2016;69:384-90.

41. Kondo T, Nakazawa H, Ito F, et al. Primary site and incidence of lymph node metastases in urothelial carcinoma of upper urinary tract. Urology 2007;69:265-9.

42. Kondo T, Hara I, Takagi T, et al. Possible role of templatebased lymphadenectomy in reducing the risk of regional node recurrence after nephroureterectomy in patients with renal pelvic cancer. Jpn J Clin Oncol 2014;44:1233-8.

43. Kondo T, Hara I, Takagi T, et al. Template-based lymphadenectomy reduces the risk of regional lymph node recurrence among patients with upper/middle ureteral cancer. Int J Clin Oncol 2017;22:145-52.

44. Matin SF, Sfakianos JP, Espiritu PN, et al. Patterns of Lymphatic Metastases in Upper Tract Urothelial Carcinoma and Proposed Dissection Templates. J Urol 2015;194:1567-74.

45. Komatsu H, Tanabe N, Kubodera S, et al. The role of lymphadenectomy in the treatment of transitional cell carcinoma of the upper urinary tract. J Urol 1997;157:1622-4.

46. Roscigno M, Brausi M, Heidenreich A, et al. Lymphadenectomy at the time of nephroureterectomy for upper tract urothelial cancer. Eur Urol 2011;60:776-83.

47. Miyake H, Hara I, Gohji K, et al. The significance of lymphadenectomy in transitional cell carcinoma of the upper urinary tract. Br J Urol 1998;82:494-8.

48. Roscigno M, Cozzarini C, Bertini R, et al. Prognostic value of lymph node dissection in patients with muscleinvasive transitional cell carcinoma of the upper urinary tract. Eur Urol 2008;53:794-802.

49. Roscigno M, Shariat SF, Margulis V, et al. Impact of lymph node dissection on cancer specific survival in patients with upper tract urothelial carcinoma treated with radical nephroureterectomy. J Urol 2009;181:2482-9.

50. Lughezzani G, Jeldres C, Isbarn H, et al. A critical appraisal of the value of lymph node dissection at nephroureterectomy for upper tract urothelial carcinoma. Urology 2010;75:118-24.

51. Mason RJ, Kassouf W, Bell DG, et al. The contemporary role of lymph node dissection during nephroureterectomy in the management of upper urinary tract urothelial carcinoma: the Canadian experience. Urology 2012;79:840-5.

52. Yang D, Chen Q, Song X, et al. Effect of lymph node dissection on the outcomes of upper tract urothelial carcinomas: a meta-analysis. Expert Rev Anticancer Ther 2014;14:667-75.

53. Chappidi MR, Kates M, Johnson MH, et al. Lymph node yield and tumor location in patients with upper tract urothelial carcinoma undergoing nephroureterectomy affects survival: A U.S. population-based analysis (20042012). Urol Oncol 2016;34:531.e15-531.e24.

54. Dominguez-Escrig JL, Peyronnet B, Seisen T, et al. Potential Benefit of Lymph Node Dissection 
During Radical Nephroureterectomy for Upper Tract Urothelial Carcinoma: A Systematic Review by the European Association of Urology Guidelines Panel on Non-muscle-invasive Bladder Cancer. Eur Urol Focus 2019;5:224-41.

55. Ikeda M, Matsumoto K, Sakaguchi K, et al. Effect of Lymphadenectomy During Radical Nephroureterectomy in Locally Advanced Upper Tract Urothelial Carcinoma. Clin Genitourin Cancer 2017;15:556-62.

56. Inokuchi J, Kuroiwa K, Kakehi Y, et al. Role of lymph node dissection during radical nephroureterectomy for upper urinary tract urothelial cancer: multi-institutional large retrospective study JCOG1110A. World J Urol 2017;35:1737-44.

57. Guo R, Zhu Y, Xiong G, et al. Role of lymph node dissection in the management of upper tract urothelial carcinomas: a meta-analysis. BMC Urol 2018;18:24.

58. Seisen T, Shariat SF, Cussenot O, et al. Contemporary role of lymph node dissection at the time of radical nephroureterectomy for upper tract urothelial carcinoma. World J Urol 2017;35:535-48.

59. Zareba P, Rosenzweig B, Winer AG, et al. Association between lymph node yield and survival among patients undergoing radical nephroureterectomy for urothelial carcinoma of the upper tract. Cancer 2017;123:1741-50.

60. El Fettouh HA, Rassweiler JJ, Schulze M, et al. Laparoscopic radical nephroureterectomy: results of an international multicenter study. Eur Urol 2002;42:447-52.

61. Huang CY, Chung SD, Wang SM, et al. An audit of nephroureterectomy for upper tract urothelial carcinoma. Eur J Surg Oncol 2009;35:1333-6.

62. Li M, Shi A, Kong W, et al. Transitional cell carcinoma with extension of the renal vein and IVC tumor thrombus: report of three cases and literature review. World J Surg Oncol 2016;14:309.

63. Singh O, George AJP, Singh JC, et al. Transitional cell carcinoma of the renal pelvis with venous tumor thrombus. Rev Urol 2017;19:145-8.

64. Juan YS, Jang MY, Shen JT, et al. Transitional cell carcinoma of the renal pelvis with extension into the inferior vena cava: a report of two cases. Kaohsiung J Med Sci 2003;19:362-7.

65. Miyazato M, Yonou H, Sugaya K, et al. Transitional cell carcinoma of the renal pelvis forming tumor thrombus in the vena cava. Int J Urol 2001;8:575-7.

66. Oba K, Suga A, Shimizu Y, et al. Transitional cell carcinoma of the renal pelvis with vena caval tumor thrombus. Int J Urol 1997;4:307-10.
67. Prando A, Prando P, Prando D. Urothelial cancer of the renal pelvicaliceal system: unusual imaging manifestations. Radiographics 2010;30:1553-66.

68. Tseng YS, Chen KH, Chiu B, et al. Renal urothelial carcinoma with extended venous thrombus. South Med J 2010;103:813-4.

69. Diaz RR, Kwon JK, Lee JY, et al. Renal pelvic urothelial carcinoma with vena caval thrombus mimicking renal cell carcinoma. Korean J Urol 2014;55:624-7.

70. Rashid S, Akhtar M. Sarcomatoid Variant of Urothelial Carcinoma of the Renal Pelvis with Inferior Vena Cava Tumour Thrombus: A Case Report and Literature Review. Case Rep Pathol 2018;2018:1837510.

71. Thiel DD, Igel TC, Wu KJ. Sarcomatoid carcinoma of transitional cell origin confined to renal pelvis. Urology 2006;67:622.e9-11.

72. Guo RQ, Hong P, Xiong GY, et al. Impact of ureteroscopy before radical nephroureterectomy for upper tract urothelial carcinomas on oncological outcomes: a metaanalysis. BJU Int 2018;121:184-93.

73. Liu Z, Zheng S, Li X, et al. Oncologic Outcomes of Patients Undergoing Diagnostic Ureteroscopy Before Radical Nephroureterectomy for Upper Urinary Tract Urothelial Carcinomas: A Systematic Review and Meta-Analysis. J Laparoendosc Adv Surg Tech A 2018;28:1316-25.

74. Tan P, Xie N, Yang L, et al. Diagnostic Ureteroscopy Prior to Radical Nephroureterectomy for Upper Tract Urothelial Carcinoma Increased the Risk of Intravesical Recurrence. Urol Int 2018;100:92-9.

75. Boorjian S, Ng C, Munver R, et al. Impact of delay to nephroureterectomy for patients undergoing ureteroscopic biopsy and laser tumor ablation of upper tract transitional cell carcinoma. Urology 2005;66:283-7.

76. Sundi D, Svatek RS, Margulis V, et al. Upper tract urothelial carcinoma: impact of time to surgery. Urol Oncol 2012;30:266-72.

77. Xia L, Taylor BL, Pulido JE, et al. Impact of surgical waiting time on survival in patients with upper tract urothelial carcinoma: A national cancer database study. Urol Oncol 2018;36:10.e15-10.e22.

78. Azémar MD, Comperat E, Richard F, et al. Bladder recurrence after surgery for upper urinary tract urothelial cell carcinoma: frequency, risk factors, and surveillance. Urol Oncol 2011;29:130-6.

79. Lughezzani G, Burger M, Margulis V, et al. Prognostic factors in upper urinary tract urothelial carcinomas: a comprehensive review of the current literature. Eur Urol 2012;62:100-14. 
80. Matsui Y, Utsunomiya N, Ichioka K, et al. Risk factors for subsequent development of bladder cancer after primary transitional cell carcinoma of the upper urinary tract. Urology 2005;65:279-83.

81. Fang D, Li XS, Xiong GY, et al. Prophylactic intravesical chemotherapy to prevent bladder tumors after nephroureterectomy for primary upper urinary tract urothelial carcinomas: a systematic review and metaanalysis. Urol Int 2013;91:291-6.

82. Millán-Rodríguez F, Chéchile-Toniolo G, SalvadorBayarri J, et al. Upper urinary tract tumors after primary superficial bladder tumors: prognostic factors and risk groups. J Urol 2000;164:1183-7.

83. Miyake H, Hara I, Kamidono S, et al. Multifocal transitional cell carcinoma of the bladder and upper urinary tract: molecular screening of clonal origin by characterizing CD44 alternative splicing patterns. J Urol 2004;172:1127-9.

84. Catto JWF, Hartmann A, Stoehr R, et al. Multifocal Urothelial Cancers With the Mutator Phenotype are of Monoclonal Origin and Require Panurothelial Treatment for Tumor Clearance. J Urol 2006;175:2323-30.

85. Habuchi T, Takahashi R, Yamada H, et al. Metachronous multifocal development of urothelial cancers by intraluminal seeding. Lancet 1993;342:1087-8.

86. Hafner C, Knuechel R, Zanardo L, et al. Evidence for oligoclonality and tumor spread by intraluminal seeding in multifocal urothelial carcinomas of the upper and lower urinary tract. Oncogene 2001;20:4910-5.

87. Lu DD, Boorjian SA, Raman JD. Intravesical chemotherapy use after radical nephroureterectomy: A national survey of urologic oncologists. Urol Oncol 2017;35:113.e1-7.

88. Tari K, Satake I, Kojima S, et al. Prophylactic intravesical chemotherapy in bladder tumors after surgery of upper tract urothelial carcinoma. Hinyokika Kiyo 1987;33:852-6.

89. Sakamoto N, Naito S, Kumazawa J, et al. Prophylactic intravesical instillation of mitomycin $\mathrm{C}$ and cytosine arabinoside for prevention of recurrent bladder tumors following surgery for upper urinary tract tumors: a prospective randomized study. Int J Urol 2001;8:212-6.

90. Wu P, Zhu G, Wei D, et al. Prophylactic intravesical chemotherapy decreases bladder tumor recurrence after nephroureterectomy for primary upper tract urothelial carcinoma: A systematic review and meta-analysis. J buon 2015;20:1229-38.
91. Yuan H, Mao X, Bai Y, et al. The effect of intravesical chemotherapy in the prevention of intravesical recurrence after nephroureterectomy for upper tract urothelial carcinoma: a meta-analysis. J Chemother 2015;27:195-200.

92. Ito A, Shintaku I, Satoh M, et al. Prospective randomized phase II trial of a single early intravesical instillation of pirarubicin (THP) in the prevention of bladder recurrence after nephroureterectomy for upper urinary tract urothelial carcinoma: the THP Monotherapy Study Group Trial. J Clin Oncol 2013;31:1422-7.

93. O'Brien T, Ray E, Singh R, et al. Prevention of bladder tumours after nephroureterectomy for primary upper urinary tract urothelial carcinoma: a prospective, multicentre, randomised clinical trial of a single postoperative intravesical dose of mitomycin $\mathrm{C}$ (the ODMIT-C Trial). Eur Urol 2011;60:703-10.

94. van Doeveren T, van Leeuwen PJ, Aben KKH, et al. Reduce bladder cancer recurrence in patients treated for upper urinary tract urothelial carcinoma: The REBACARE-trial. Contemp Clin Trials Commun 2018;9:121-9.

95. Miyamoto K, Ito A, Wakabayashi M, et al. A Phase III trial of a single early intravesical instillation of pirarubicin to prevent bladder recurrence after radical nephroureterectomy for upper tract urothelial carcinoma (JCOG1403, UTUC THP Phase III). Jpn J Clin Oncol 2018;48:94-7.

96. Moriarty MA, Uhlman MA, Bing MT, et al. Evaluating the safety of intraoperative instillation of intravesical chemotherapy at the time of nephroureterectomy. BMC Urol 2015;15:45.

97. Noennig B, Bozorgmehri S, Terry R, et al. Evaluation of Intraoperative Versus Postoperative Adjuvant Mitomycin C with Nephroureterectomy for Urothelial Carcinoma of the Upper Urinary Tract. Bladder Cancer 2018;4:389-94.

98. Chang SS, Bochner BH, Chou R, et al. Treatment of NonMetastatic Muscle-Invasive Bladder Cancer: AUA/ASCO/ ASTRO/SUO Guideline. J Urol 2017;198:552-9.

99. Flaig TW, Spiess PE, Agarwal N, et al. NCCN Guidelines Insights: Bladder Cancer, Version 5.2018. J Natl Compr Canc Netw 2018;16:1041-53.

100.Hellenthal NJ, Shariat SF, Margulis V, et al. Adjuvant chemotherapy for high risk upper tract urothelial carcinoma: results from the Upper Tract Urothelial Carcinoma Collaboration. J Urol 2009;182:900-6.

101. Yafi FA, Tanguay S, Rendon R, et al. Adjuvant chemotherapy for upper-tract urothelial carcinoma treated with nephroureterectomy: assessment of adequate 
renal function and influence on outcome. Urol Oncol 2014;32:31.e17-24.

102.Leow JJ, Martin-Doyle W, Fay AP, et al. A systematic review and meta-analysis of adjuvant and neoadjuvant chemotherapy for upper tract urothelial carcinoma. Eur Urol 2014;66:529-41.

103.Porten S, Siefker-Radtke AO, Xiao L, et al. Neoadjuvant chemotherapy improves survival of patients with upper tract urothelial carcinoma. Cancer 2014;120:1794-9.

104. Shirotake S, Kikuchi E, Tanaka N, et al. Impact of an adjuvant chemotherapeutic regimen on the clinical outcome in high risk patients with upper tract urothelial carcinoma: a Japanese multi-institution experience. J Urol 2015;193:1122-8.

105. Fujita K, Inamoto T, Yamamoto Y, et al. Role of adjuvant chemotherapy for lymph node-positive upper tract urothelial carcinoma and the prognostic significance of C-reactive protein: A multi-institutional, retrospective study. Int J Urol 2015;22:1006-12.

106.Almassi N, Gao T, Lee B, et al. Impact of Neoadjuvant Chemotherapy on Pathologic Response in Patients With Upper Tract Urothelial Carcinoma Undergoing Extirpative Surgery. Clin Genitourin Cancer 2018;16:e1237-42.

107.Aziz A, Dobruch J, Hendricksen K, et al. Perioperative chemotherapy in upper tract urothelial carcinoma: a comprehensive review. World J Urol 2017;35:1401-7.

108. Gregg RW, Vera-Badillo FE, Booth CM, et al. Perioperative chemotherapy for urothelial carcinoma of the upper urinary tract: A systematic review and metaanalysis. Crit Rev Oncol Hematol 2018;128:58-64.

109. Hosogoe S, Hatakeyama S, Kusaka A, et al. Platinumbased Neoadjuvant Chemotherapy Improves Oncological Outcomes in Patients with Locally Advanced Upper Tract Urothelial Carcinoma. Eur Urol Focus 2018;4:946-53.

110.Ikeda M, Matsumoto K, Hirayama T, et al. Selected HighRisk Patients With Upper Tract Urothelial Carcinoma Treated With Radical Nephroureterectomy for Adjuvant Chemotherapy: A Multi-Institutional Retrospective Study. Clin Genitourin Cancer 2018;16:e669-75.

111. Kim DK, Lee JY, Kim JW, et al. Effect of neoadjuvant chemotherapy on locally advanced upper tract urothelial carcinoma: A systematic review and meta-analysis. Crit Rev Oncol Hematol 2019;135:59-65.

112. Kubota Y, Hatakeyama S, Tanaka T, et al. Oncological outcomes of neoadjuvant chemotherapy in patients with locally advanced upper tract urothelial carcinoma: a multicenter study. Oncotarget 2017;8:101500-8.
113. Nakagawa T, Komemushi Y, Kawai T, et al. Efficacy of post-nephroureterectomy cisplatin-based adjuvant chemotherapy for locally advanced upper tract urothelial carcinoma: a multi-institutional retrospective study. World J Urol 2017;35:1569-75.

114. Nazzani S, Preisser F, Mazzone E, et al. Survival effect of perioperative systemic chemotherapy on overall mortality in locally advanced and/or positive regional lymph node non-metastatic urothelial carcinoma of the upper urinary tract. World J Urol 2019;37:1329-37.

115. Seisen T, Krasnow RE, Bellmunt J, et al. Effectiveness of Adjuvant Chemotherapy After Radical Nephroureterectomy for Locally Advanced and/or Positive Regional Lymph Node Upper Tract Urothelial Carcinoma. J Clin Oncol 2017;35:852-60.

116. Necchi A, Lo Vullo S, Mariani L, et al. Adjuvant chemotherapy after radical nephroureterectomy does not improve survival in patients with upper tract urothelial carcinoma: a joint study by the European Association of Urology-Young Academic Urologists and the Upper Tract Urothelial Carcinoma Collaboration. BJU Int 2018;121:252-9.

117. Gin GE, Ruel NH, Kardos SV, et al. Utilization of perioperative systemic chemotherapy in upper tract urothelial carcinoma. Urol Oncol 2017;35:192-200.

118. Cohen A, Kuchta K, Park S. Neoadjuvant and adjuvant chemotherapy use in upper tract urothelial carcinoma. Urol Oncol 2017;35:322-7.

119. Rajput MZ, Kamat AM, Clavell-Hernandez J, et al. Perioperative outcomes of laparoscopic radical nephroureterectomy and regional lymphadenectomy in patients with upper urinary tract urothelial carcinoma after neoadjuvant chemotherapy. Urology 2011;78:61-7.

120. Seisen T, Jindal T, Karabon P, et al. Efficacy of Systemic Chemotherapy Plus Radical Nephroureterectomy for Metastatic Upper Tract Urothelial Carcinoma. Eur Urol 2017;71:714-8.

121. Birtle AJ, Chester JD, Jones RJ, et al. Results of POUT: A phase III randomised trial of perioperative chemotherapy versus surveillance in upper tract urothelial cancer (UTUC). J Clin Oncol 2018;36:abstr 407.

122. Capitanio U, Shariat SF, Isbarn H, et al. Comparison of oncologic outcomes for open and laparoscopic nephroureterectomy: a multi-institutional analysis of 1249 cases. Eur Urol 2009;56:1-9.

123. Peyronnet B, Seisen T, Dominguez-Escrig JL, et al. Oncological Outcomes of Laparoscopic Nephroureterectomy Versus Open Radical 
Nephroureterectomy for Upper Tract Urothelial Carcinoma: An European Association of Urology Guidelines Systematic Review. Eur Urol Focus 2019;5:205-23.

124. Ni S, Tao W, Chen Q, et al. Laparoscopic versus open nephroureterectomy for the treatment of upper urinary tract urothelial carcinoma: a systematic review and cumulative analysis of comparative studies. Eur Urol 2012;61:1142-53.

125.Liu F, Guo W, Zhou X, et al. Laparoscopic versus open nephroureterectomy for upper urinary tract urothelial carcinoma: A systematic review and meta-analysis. Medicine (Baltimore) 2018;97:e11954.

126. Nouralizadeh A, Tabatabaei S, Basiri A, et al. Comparison of Open Versus Laparoscopic Versus Hand-Assisted Laparoscopic Nephroureterectomy: A Systematic Review and Meta-Analysis. J Laparoendosc Adv Surg Tech A 2018;28:656-81.

Cite this article as: Barton GJ, Tan WP, Inman BA. The nephroureterectomy: a review of technique and current controversies. Transl Androl Urol 2020;9(6):3168-3190. doi: 10.21037/tau.2019.12.07
127. Rouprêt $M$. Is there currently enough evidence to assess whether laparoscopic nephroureterectomy is safe to treat urothelial carcinoma of the upper urinary tract? Eur Urol 2012;61:1154-5.

128. Ariane MM, Colin P, Ouzzane A, et al. Assessment of oncologic control obtained after open versus laparoscopic nephroureterectomy for upper urinary tract urothelial carcinomas (UUT-UCs): results from a large French multicenter collaborative study. Ann Surg Oncol 2012;19:301-8.

129. Soodana-Prakash N, Balise R, Nahar B, et al. Perioperative outcomes and complication predictors associated with open and minimally invasive nephroureterectomy. Can J Urol 2018;25:9395-400.

130. Rodriguez JF, Packiam VT, Boysen WR, et al. Utilization and Outcomes of Nephroureterectomy for Upper Tract Urothelial Carcinoma by Surgical Approach. J Endourol 2017;31:661-5. 